\title{
¿Upstream Extension of a Bottom-Advected Plume and Its Mechanism: The Case of the Yellow Rivero
}

\author{
Xiaojie Yu, ${ }^{\mathrm{a}, \mathrm{b}}$ Xinyu Guo, ${ }^{\mathrm{a}, \mathrm{c}}$ Huiwang GaO, ${ }^{\mathrm{a}, \mathrm{b}}$ and Tao Zou ${ }^{\mathrm{d}}$ \\ ${ }^{\text {a }}$ Key Laboratory of Marine Environment and Ecology, Ministry of Education, Ocean University of China, Qingdao, China \\ ${ }^{\mathrm{b}}$ Laboratory for Marine Ecology and Environmental Sciences, Qingdao National Laboratory for Marine \\ Science and Technology, Qingdao, China \\ ${ }^{\mathrm{c}}$ Center for Marine Environmental Studies, Ehime University, Matsuyama, Japan \\ ${ }^{\mathrm{d}}$ Key Laboratory of Coastal Zone Environmental Processes and Ecological Remediation, Yantai Institute of \\ Coastal Zone Research, Chinese Academy of Sciences, Yantai, China
}

(Manuscript received 29 September 2020, in final form 14 April 2021)

\begin{abstract}
Hydrographic surveys have revealed that the Yellow River plume propagates in the direction opposite to that of a Kelvin wave (upstream) under a low river discharge condition, but turns downstream as the river discharge increases. A numerical model reproduced the upstream extension of the plume under the low river discharge condition and the transition to the downstream direction under the high river discharge condition, and confirmed that the summer wind is not the necessary condition for upstream extension of the plume. With the condition of low river discharge, the model also indicated the dependence of the upstream extension of the plume on the tidal range: extending upstream in spring tide but turning downstream in neap tide. The upstream movement of the plume results from the upstream transport of freshwater that depends on the upstream tide-induced residual current around the river mouth and the downstream density-driven current around the offshore plume front. With the condition of high river discharge, the upstream tide-induced residual current cannot compete with the downstream density-driven current and the plume turns downstream. Momentum analysis confirms the important roles of advection term and viscosity term in the condition of low river discharge and the shift to a Coriolis force-dominated system under high river discharge condition. An idealized model study suggests a dimensionless number for the river discharge changing the river plume extension from upstream to downstream under a specific upstream ambient current around the river mouth.
\end{abstract}

KEYWORDS: Estuaries; Baroclinic flows; Buoyancy; Freshwater; Tides; Numerical analysis/modeling

\section{Introduction}

River discharge is a major buoyancy source in coastal regions. As the lighter freshwater encounters the denser seawater, a river plume with a sharp density front between the two types of water is formed. In terms of the structure of the density front, the river plume can be categorized as bottom advected or surface advected (Yankovsky and Chapman 1997). For the bottom-advected plume, the low-salinity water occupies the entire water column and turns immediately downstream (in the form of Kelvin wave) after it flows out of the estuary mouth. For the surface-advected plume, the lighter water primarily remains in the surface layer and detaches from the bottom. In this case, the plume has two distinct features: an anticyclonic bulge near the river mouth and a downstream coastal current. A realistic river plume should be somewhere between the two extreme types depending on a variety of factors such as river discharge, bathymetry, and vertical mixing induced by tides and winds.

¿ Denotes content that is immediately available upon publication as open access.

Supplemental information related to this paper is available at the Journals Online website: https://doi.org/10.1175/JPO-D-200235.s1.

Corresponding author: Xinyu Guo,guoxinyu@sci.ehime-u.ac.jp
Many numerical simulations produced the upstream extension of a plume, which spread in a direction opposite to that of a Kelvin wave (e.g., Chao and Boicourt 1986; Chapman and Lenz 1994; Garvine 2001; Matano and Palma 2010). Various mechanisms have been proposed for the upstream extension, including unrealistic model configurations of a simple inlet or a deep coastal wall (Garvine 2001), oversimplification of the boundary condition (Yankovsky 2000), geostrophic adjustment (Chapman and Lenz 1994; Matano and Palma 2010), and nongeostrophic acceleration (Kourafalou et al. 1996). A universal effective remedy to arrest the upstream development is to add a downstream ambient current (Chapman and Lenz 1994; Yankovsky and Chapman 1997).

The tides have been reported to be important to the behavior of a river plume. Isobe (2005) demonstrated that unstable freshwater accumulating in a bulge can be restricted to the alongshore direction by the alongshore tidal currents. $\mathrm{Li}$ and Rong (2012) also found that the tidal currents could stabilize the Changjiang River plume bulge and force the plume water to move in the direction of the tidal currents. Using numerical experiments with and without tide, Guo and Valle-Levison (2007) found that the upstream extension of the plume in the Chesapeake Bay is well inhibited after considering the effect of the tide. Wu et al. (2011) also pointed out that with tidal forcing, the unrealistic upstream extension of the Changjiang River plume in the no-tidalforcing case is restricted. All these studies demonstrated the effect of tidal current or tidal mixing on the extension of river 
plume, but paid no attention on the possible influence of tide-induced residual current as an ambient current on the river plume.

There is a fundamental problem: is the upstream extension of a river plume a consequence of model configuration or a naturally existing phenomenon? Some observational evidence for the upstream extension of a river plume in real oceans exists. Magome and Isobe (2003) observed an upstream extension in the bulge after a peak value of river discharge in SuoNada, Seto Inland Sea, and deduced that the onshore current in the bottom layer beneath the bulge transported the bulge in the upstream direction. Beardsley et al. (1985) observed the upstream extension of the Changjiang River plume. Wu et al. (2014) suggested that the coastal current from Changjiang estuary due to tide-induced Stokes drift is the major mechanism driving such upstream extension.

The Yellow River is the second largest river in China and is famous for its huge sediment load contribution to the sea. In recent decades, however, it has experienced a dramatic decreasing in freshwater and sediment fluxes into the sea due to climate change and anthropogenic activities (Wang et al. 2006). Subsequently, a series of consequences have occurred, such as a frequent occurrence of no water events in some parts of the river, accumulation of sediment in the river, and increasing of salinity in the Bohai Sea, its receiver (Lin et al. 2001; Wu et al. 2004). Since 2002, the Yellow River Conservancy Commission (YRCC) has implemented a water-sediment regulation scheme (WSRS) to reshape the relationship between the water and sediment in the river by releasing a large amount of water in a short time in summer to flush out sediments from the river into the Bohai Sea.

The WSRS provides us an opportunity to observe how the river discharge affects the movement of a plume. During the implementation of the WSRS, the Yellow River discharge increases from less than $500 \mathrm{~m}^{3} \mathrm{~s}^{-1}$ to larger than $3500 \mathrm{~m}^{3} \mathrm{~s}^{-1}$ in a period of less than 2 weeks. Wang et al. (2011) conducted three field surveys, one each before, during, and after the implementation of the WSRS in 2009. They found that the plume propagated upstream before the water release, and turned downstream during and after it. However, the mechanism for the upstream extension of the Yellow River plume when the river discharge was low, the reason for the change in the direction of the plume to downstream after the river discharge was increased, and the role of summer wind in the upstream extension of the plume remain unknown.

Our objectives are to examine whether the upstream extension of the Yellow River plume occurs occasionally or regularly by analyzing historical field survey data, and to clarify the mechanism responsible for the upstream extension under low river discharge condition and downstream extension under high river discharge condition by numerical modeling. To generalize the influence of variation in river discharge on the plume extension direction, idealized numerical studies are also needed. Previous studies on the Yellow River plume were mainly concerned about the seasonal variation in the distribution of low-salinity water, and included observational surveys (Guan and Chen 1964; Zhou et al. 1991, 1997) and numerical modeling (Wang et al. 2008). All the results showed
TABLE 1. Dates of the observations and the corresponding Yellow River discharges.

\begin{tabular}{lcc}
\hline \hline Year & Date & River discharge $\left(\mathrm{m}^{3} \mathrm{~s}^{-1}\right)$ \\
\hline 2009 & 19 Jun & 173 \\
& 1 Jul & 3600 \\
2013 & 19 Jul & 478 \\
& 24-26 Jun & 2100 \\
& 26-28 Jul & 3310 \\
2014 & 23-25 Sep & 345 \\
& 12-14 Jun & 400 \\
& 7-8 Jul & 3000 \\
& 17-20 Jul & 300 \\
\hline
\end{tabular}

that the low-salinity water from the Yellow River extends southward into the Laizhou Bay in winter and propagates northeastward into the central Bohai Sea in summer. However, studies about the influence of sharp variations in river discharge on the Yellow River plume are limited, although there are some studies in other river plume showing that the sharp variation in river discharge can induce a partially detached plume (Yankovsky et al. 2001; Jurisa and Chant 2012).

The remainder of this paper is organized as follows. Section 2 describes the observational data and model configuration, and section 3 presents the observations and model results about the extension of the Yellow River plume. Section 4 examines the mechanism for the upstream extension of the Yellow River plume through numerical experiments and analyzes how the river discharge and summer wind influence the upstream extension. The results of this study are summarized in section 5 .

\section{Observational data and model description}

Yantai Institute of Coastal Zone Research, Chinese Academy of Sciences, carried out field surveys around the Yellow River estuary before, during, and after the implementation of the WSRS in 2013 and 2014 using similar stations as Wang et al. (2011), who reported the results of a similar survey in 2009. The observational dates and corresponding Yellow River discharges in the three years are shown in Table 1. The observational stations (positions shown in section 3a) comprise six sections from the river mouth. Each section has 5-9 stations, where water temperature and salinity are measured by conductivity-temperature-depth profilers (CTDs) over the entire depth. In 2009, three fishing boats were employed, with each covering two sections. The boats started observations at the same time in the early morning and covered all the sections within $\sim 12 \mathrm{~h}$. In 2013 and 2014, only one fishing boat was employed. The survey was conducted for three days on average, with each day starting from early morning and lasting for approximately $12 \mathrm{~h}$. The tidal current around the Yellow River mouth has a semidiurnal period and a magnitude of $\sim 0.5 \mathrm{~m} \mathrm{~s}^{-1}$ that can induce an intratidal movement of plume by $\sim 10 \mathrm{~km}$. As shown later, such distance does not affect the difference of salinity in the surveys in 2009 as well as those in 2013 and 2014. On the other hand, the three fishing boats in 2009 started at the same time and the one fishing boat in 2013 and 2014 observed every two sections at almost the same time 
every day. Since the phase difference between three boats in 2009 and that between different days in 2013 and 2014 are small, our observed salinity field does not contain its maximum intratidal motion, which also guarantee the little influence of intratidal variation on the difference among the observed salinity fields from different surveys.

The river discharge recorded at Station Lijin, the hydrological station nearest to the river mouth $(\sim 100 \mathrm{~km}$ away), was obtained from www.yrcc.gov.cn. In general, the river discharge was low in the first survey $\left(150-400 \mathrm{~m}^{3} \mathrm{~s}^{-1}\right)$, increased significantly in the second survey $\left(>3000 \mathrm{~m}^{3} \mathrm{~s}^{-1}\right)$, and decreased again in the third survey $\left(300-500 \mathrm{~m}^{3} \mathrm{~s}^{-1}\right)$ (Table 1). Although the wind velocity over the sea was not recorded during the surveys in the three years, the reanalysis data from the European Centre for Medium-Range Weather Forecasts (ECMWF) shows that the prevailing winds were southerly during most surveys in the three years, with the wind speed ranging from 3 to $7 \mathrm{~m} \mathrm{~s}^{-1}$. Only during the survey in September 2014, which was the third survey in 2014, the wind was northerly with a speed of approximately $9 \mathrm{~m} \mathrm{~s}^{-1}$.

The numerical model we adopted is a three-dimensional primitive equation ocean model, the Princeton Ocean Model (POM) (Blumberg and Mellor 1987; Mellor 2003). It uses a second momentum turbulent closure scheme to calculate the vertical eddy viscosity and diffusivity (Mellor and Yamada 1982) and the Smagorinsky formulation to parameterize the horizontal eddy viscosity and diffusivity (Smagorinsky 1963).

The model domain and bathymetry are shown in Fig. 1a. The horizontal resolution is $\sim 1 \mathrm{~km}\left(1 / 90^{\circ}\right)$, which is nested by the ratio of $1: 5$ to a coarse grid model $\left(1 / 18^{\circ}\right)$ (Fig. $1 \mathrm{~b}$; Wang et al. 2008). The coarse grid model covers the Bohai Sea, Yellow Sea, and East China Sea, and focuses on the seasonal variation in the Yellow River plume. Being the same as the coarse grid model, we set 21 sigma layers in the vertical direction in the fine grid model, with the sigma values of $0,-0.002,-0.004,-0.01$, $-0.02,-0.04,-0.06,-0.08,-0.10,-0.12,-0.14,-0.17$, $-0.20,-0.30,-0.40,-0.50,-0.65,-0.80,-0.90,-0.95$, and -1 from the sea surface to the sea bottom. The bathymetry and forcing conditions for the fine grid model were interpolated linearly from those of the coarse grid model, except for the bathymetry near the Yellow River mouth that was modified by the chart in 2009 to represent the recent changes in the geography of the Yellow River delta.

The forcing conditions for the model to reproduce a climatological state included monthly wind stress, monthly heat flux, monthly river discharge, monthly precipitation, monthly evaporation, and monthly sea surface pressure (Wang et al. 2008). Four rivers were considered in the fine grid model: Yellow River, Liaohe River, Luanhe River, and Haihe River (Fig. 1a). The open boundary was set along $122.3^{\circ} \mathrm{E}$, where the bathymetry and monthly temperature, salinity, residual currents, and sea level in every five grids were set to be equal to those at the corresponding grid of the coarse grid model. Four tidal constituents $\left(\mathrm{M}_{2}, \mathrm{~S}_{2}, \mathrm{~K}_{1}\right.$, and $\left.\mathrm{O}_{1}\right)$, whose information was also provided by the coarse grid model, were considered. The currents were specified at the open boundary using a linear combination of the tidal current and residual current (Wang et al. 2008). The fine grid model under the abovementioned

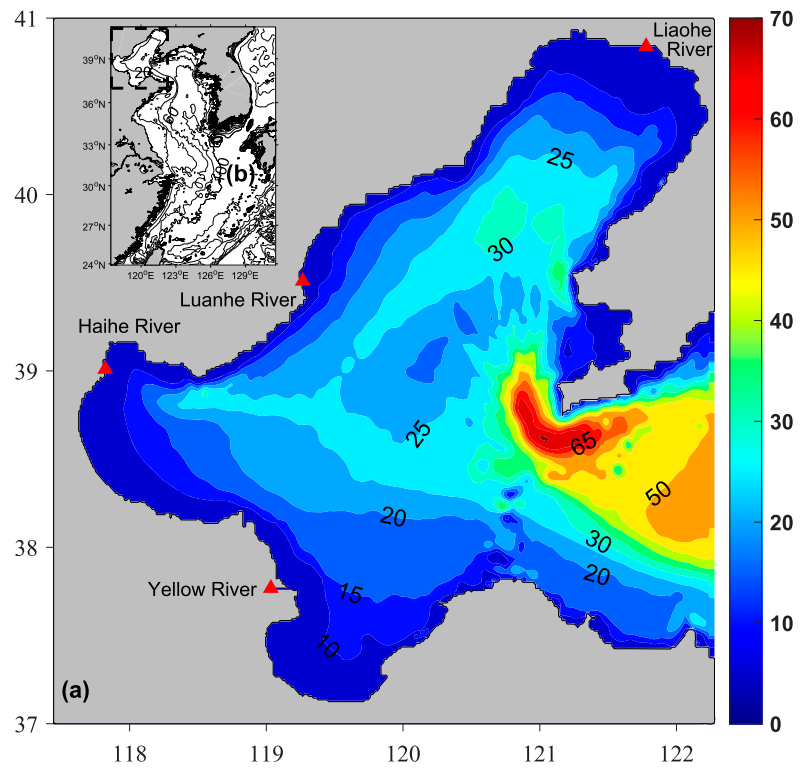

FIG. 1. Model domain and bathymetry of (a) the fine grid model and (b) the coarse grid model. The red triangles in (a) denote the positions of rivers.

forcing reached a quasi-equilibrium state after 3 years of integration (case 0) from the initial condition on 1 December, which was obtained from the coarse grid model.

After finishing the spinup of the fine grid model with the abovementioned climatological forcing, we carried out the calculations for 2009 (case a), 2013 (case b), and 2014 (case c), in which the daily Yellow River discharge (Fig. 2a) and 6-hourly wind stress were used to replace those applied in the spinup. In both 2009 and 2014, the river discharge increased from less than $500 \mathrm{~m}^{3} \mathrm{~s}^{-1}$ to more than $3500 \mathrm{~m}^{3} \mathrm{~s}^{-1}$, and then decreased to less than $500 \mathrm{~m}^{3} \mathrm{~s}^{-1}$ during one month (Fig. 2a). In 2013, the WSRS was conducted twice, and each lasted for one month. The 6-hourly wind stress for the fine grid model was spatially linearly interpolated from the ECMWF, whose spatial resolution is $0.125^{\circ} \times 0.125^{\circ}$. The daily mean wind stress near the Yellow River mouth is shown in Fig. 2b. In summer, the area around the Yellow River mouth is covered mostly by southerly wind and occasionally by weak northerly wind. The calculations for 2009, 2013, and 2014 were started from the same initial condition, that is, the climatological model results on 1 January in the third year (case 0), and performed for one year using realistic Yellow River discharges and winds to simulate the Yellow River plume in each year.

We set a series of numerical experiments (Table 2) to examine the effects of the Yellow River discharge, tide, and wind forcing on the movement of Yellow River plume. In case 1, the Yellow River discharge in 2009 and tide were considered. Case 2 examined the tide and tide-induced residual current around the Yellow River mouth. To know influences of wind forcing, we chose three types of winds and applied them to the cases designed for spring tide (9-11 June, cases 3-5) and neap tide (17-19 June, cases 6-8). The three types of winds are monthly wind stress in June 2009 (eastward component of wind stress 

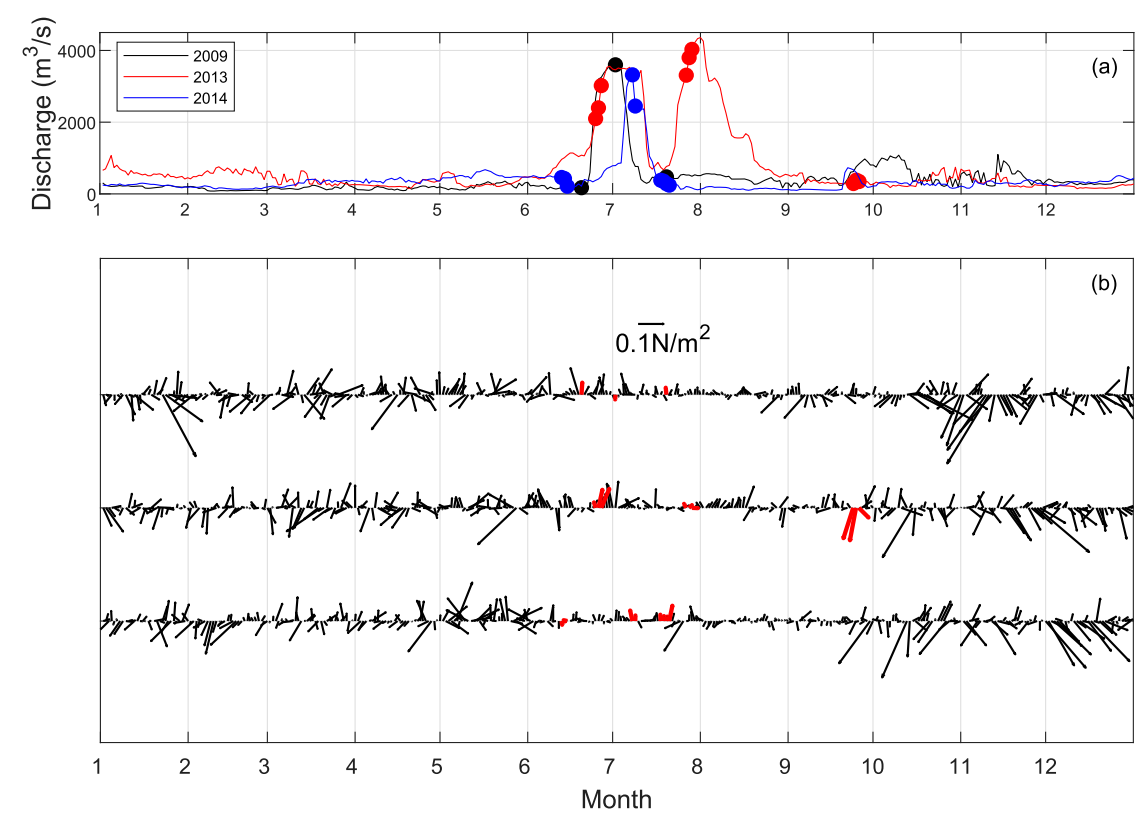

FIG. 2. (a) Daily Yellow River discharges recorded at Station Lijin in 2009, 2013, and 2014, and (b) daily mean wind stress from the ECMWF near the Yellow River mouth in 2009, 2013, and 2014 (shown from top to bottom). The dots in (a) indicate the river discharges on the surveyed days in different years, and the red arrows in (b) denote the wind stresses on the same days.

was $0.001 \mathrm{~N} \mathrm{~m}^{-2}$ and northward component was $0.02 \mathrm{~N} \mathrm{~m}^{-2}$, corresponding to a wind speed of $\left.3.8 \mathrm{~m} \mathrm{~s}^{-1}\right)$, the strong southwesterly wind stress appearing on 1 June 2009 (eastward component was $0.03 \mathrm{~N} \mathrm{~m}^{-2}$ and northward component was $0.05 \mathrm{~N} \mathrm{~m}^{-2}$, corresponding to a wind speed of $6.5 \mathrm{~m} \mathrm{~s}^{-1}$ ), and the strong northeasterly wind stress appearing on 9 May 2009 (eastward component was $-0.06 \mathrm{~N} \mathrm{~m}^{-2}$ and northward component was $-0.05 \mathrm{~N} \mathrm{~m}^{-2}$, corresponding to a wind speed of $7.1 \mathrm{~m} \mathrm{~s}^{-1}$ ). The model results were saved hourly, and a low-pass filter (Hanawa and Mitsudera 1985) was used to remove the tidal components.

We also set an idealized numerical model to generalize the influence of variation in river discharge on the river plume extension direction under an ambient current. The model domain has a meridional range of $80 \mathrm{~km}$ and a zonal range of $200 \mathrm{~km}$ and the water depth linearly increases from $1 \mathrm{~m}$ inside a river course at the western boundary to $15 \mathrm{~m}$ at the eastern boundary (their figure is presented in section $4 \mathrm{~b}$ ). The model

TABLE 2. List of numerical experiments. All the cases except case 2 considered the surface heat flux.

\begin{tabular}{|c|c|c|c|}
\hline Realistic cases & Yellow River discharge & Wind forcing & \\
\hline Case 0 & Monthly climatology & Monthly climatology & \\
\hline Case a & Daily in 2009 & Hourly in 2009 & \\
\hline Case b & Daily in 2013 & Hourly in 2013 & \\
\hline Case c & Daily in 2014 & Hourly in 2014 & \\
\hline Sensitivity cases & Yellow River discharge & Wind forcing & Tide \\
\hline Case 1 & Daily in 2009 & No wind & \\
\hline Case 2 & No discharge & No wind & \\
\hline Case 3 & Daily in 2009 & Average in June 2009 & Spring tide \\
\hline Case 4 & Daily in 2009 & Strong southwesterly on 1 Jun 2009 & Spring tide \\
\hline Case 5 & Daily in 2009 & Strong northeasterly on 9 May 2009 & Spring tide \\
\hline Case 6 & Daily in 2009 & Average in June 2009 & Neap tide \\
\hline Case 7 & Daily in 2009 & Strong southwesterly on 1 Jun 2009 & Neap tide \\
\hline Case 8 & Daily in 2009 & Strong northeasterly on 9 May 2009 & Neap tide \\
\hline Idealized cases & River discharge & Ambient current & Tidal current amplitude \\
\hline Cases 9-488 & $100: 100: 3000\left(\mathrm{~m}^{3} \mathrm{~s}^{-1}\right)$ & $-0.05: 0.01: 0.10\left(\mathrm{~m} \mathrm{~s}^{-1}\right)$ & $0.1 \mathrm{~m} \mathrm{~s}^{-1}$ \\
\hline Cases 489-968 & $100: 100: 3000\left(\mathrm{~m}^{3} \mathrm{~s}^{-1}\right)$ & $-0.05: 0.01: 0.10\left(\mathrm{~m} \mathrm{~s}^{-1}\right)$ & $1 \mathrm{~m} \mathrm{~s}^{-1}$ \\
\hline
\end{tabular}



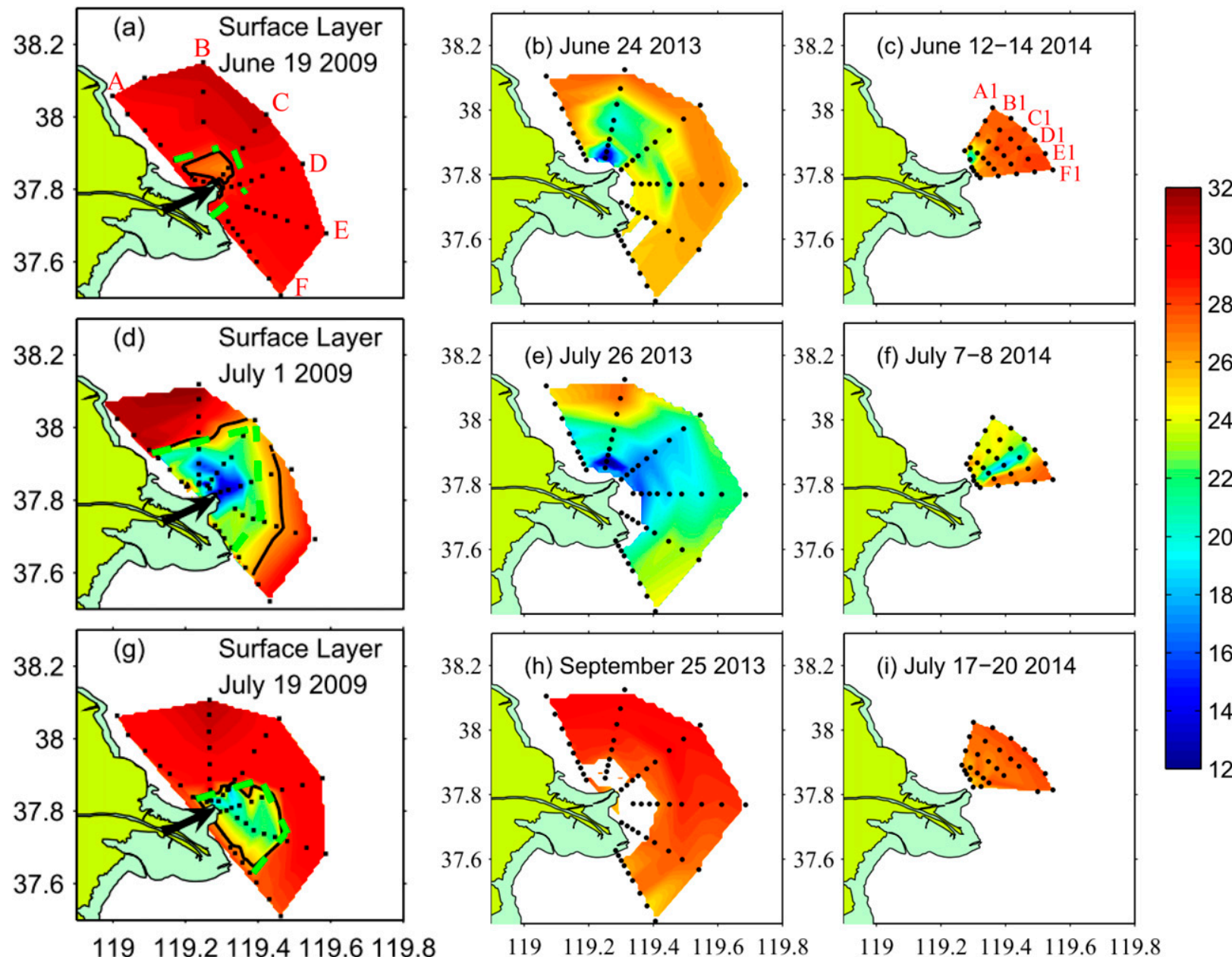

FIG. 3. Horizontal distributions of observed sea surface salinity (top) before, (middle) during, and (bottom) after implementation of the WSRS in (a),(d),(g) 2009; (b),(e),(h) 2013; and (c),(f),(i) 2014. The black dots denote the survey stations. The distribution in 2009 is directly derived from Wang et al. (2011). Characters A-F in (a) and A1-F1 in (c) represent the sections in 2009 and 2014, respectively, along which the vertical distributions of salinity are shown in Fig. 4.

resolution is $1 \mathrm{~km}$ in the horizontal direction and 21 sigma layers in the vertical direction. The angle between the river course and the northward direction is $90^{\circ}$. The river discharge is imposed as vertical freshwater flux to the surface layer over the river course. Only the $\mathrm{M}_{2}$ tide is included in the model. Because the tide-induced residual current around the river mouth is negligible small, an ambient current resembling the tide-induced residual current around the Yellow River mouth is applied along both southern and northern boundaries of the model domain.

We set a series of numerical experiments to examine how the river discharge, ambient current and tidal current affect the river plume in this idealized case (Table 2). In these experiments, the river discharge varies from 100 to $3000 \mathrm{~m}^{3} \mathrm{~s}^{-1}$ with an interval of $100 \mathrm{~m}^{3} \mathrm{~s}^{-1}$; the specified ambient current varies from $-0.05 \mathrm{~m} \mathrm{~s}^{-1}$ (southward) to $0.10 \mathrm{~m} \mathrm{~s}^{-1}$ (northward) with an interval of $0.01 \mathrm{~m} \mathrm{~s}^{-1}$. We considered two situations for the tidal current amplitude around the river mouth $\left(0.1\right.$ or $\left.1 \mathrm{~m} \mathrm{~s}^{-1}\right)$. In each experiment, the model was run for 30 days from rest, and we obtained the subtidal results on the 25 th day by applying a low-pass filter (Hanawa and Mitsudera 1985) to the hourly model results from the 20 th day to the 30 th day.

\section{Results}

\section{a. Field observations}

The horizontal distributions of the observed sea surface salinity before, during, and after the implementation of the WSRS in the 3 years are shown in Fig. 3. In 2009, the lowsalinity water was concentrated in the direction upstream of the Yellow River mouth on 19 June (Fig. 3a) when the river discharge was $173 \mathrm{~m}^{3} \mathrm{~s}^{-1}$. However, it became symmetrical around the river mouth on 1 July (Fig. 3d) when river discharge increased to $3600 \mathrm{~m}^{3} \mathrm{~s}^{-1}$. After the river discharge subsided to $478 \mathrm{~m}^{3} \mathrm{~s}^{-1}$ on 19 July, the plume turned downstream (Fig. $3 \mathrm{~g}$ ).

The change in the Yellow River plume pattern before and during the WSRS also occurred in 2013, when low-salinity 

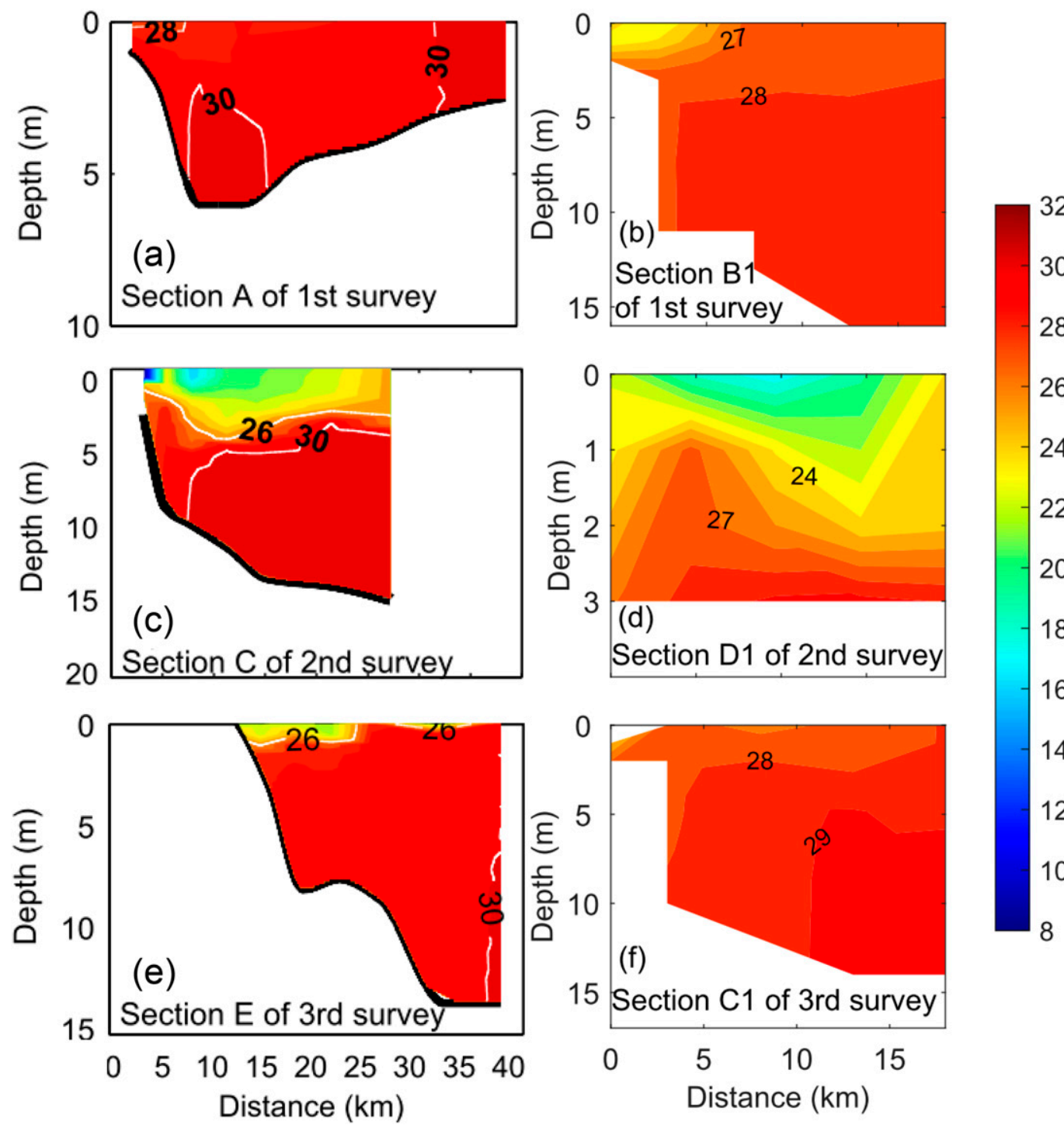

FIG. 4. Vertical distributions of salinity along the sections where observed low-salinity water concentrated (top) before, (middle) during, and (bottom) after implementation of the WSRS in (a),(c),(e) 2009 and (b),(d),(f) 2014. Salinity distributions shown for section A in (a), section C in (c), section E in (e), section B1 in (b), section D1 in (d), and section $\mathrm{C} 1$ in (f). The distribution in 2009 is derived directly from Wang et al. (2011).

water was found to be distributed upstream on 24 June (Fig. 3b), and symmetrically near the river mouth on 26 July (Fig. 3e). Owing to the lack of data in the stations near the river mouth on 25 September, the distribution of lowsalinity water after the reduction in the river discharge was not clear (Fig. 3h). In 2014, the coverage of the observational stations was narrower than those in 2009 and 2013. However, the results also showed that the plume was distributed in the upstream area (Fig. 3c) when the river discharge was low $\left(400 \mathrm{~m}^{3} \mathrm{~s}^{-1}\right)$, and extended northeastward (Fig. 3f) when the discharge increased to $3000 \mathrm{~m}^{3} \mathrm{~s}^{-1}$. After the river discharge subsided, the low-salinity water was not easily confirmed from the observation (Fig. 3i) because the low-salinity water possibly extended beyond the survey region. The wind conditions before the WSRS were upwelling favorable in 2009 and 2013, but downwelling favorable in 2014 (Fig. 2b). After the WSRS, they were upwelling favorable in 2009 and 2014, but downwelling favorable in 2013 (Fig. 2b).

Therefore, under normal conditions when the river discharge was low, the Yellow River plume likely extended upstream in summer, which is different from the downstream extension of the Kelvin wave. Under abnormal conditions when the river discharge increased sharply, the Yellow River plume gradually turned downstream.

We have shown the vertical distributions of salinity along the sections where low-salinity water concentrated in 2009 and 2014 (Fig. 4); this information is not shown for 2013 when 

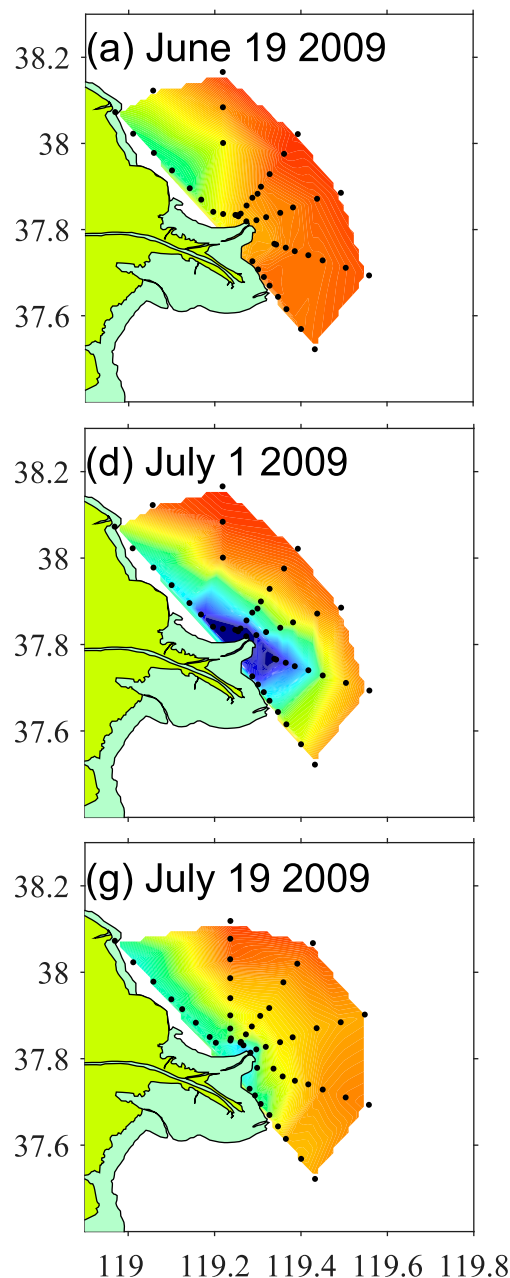
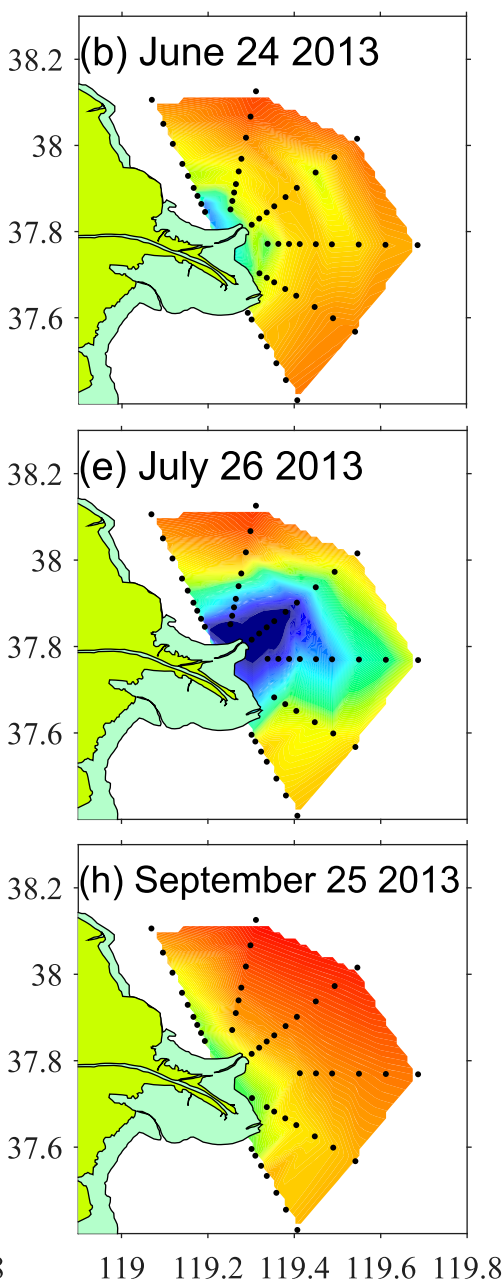

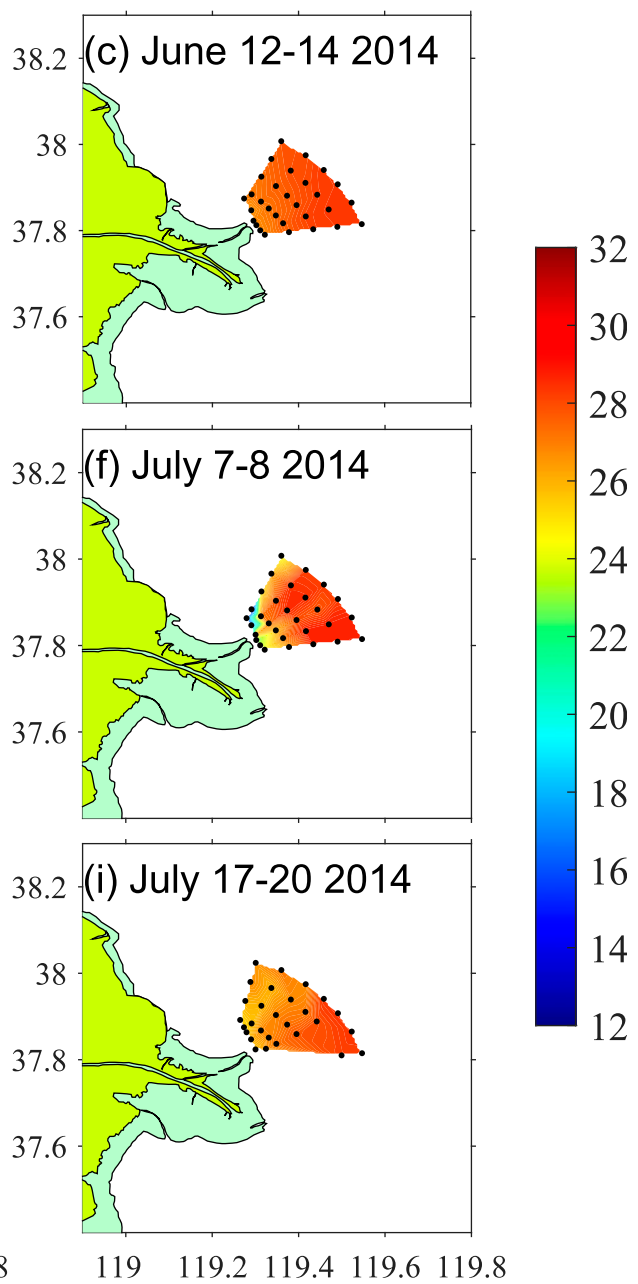

FIG. 5. Horizontal distributions of modeled sea surface salinity at the observational stations before (top) before, (middle) during, and (bottom) after implementation of the WSRS in (a),(d),(g) 2009 (case a); (b),(e),(h) 2013 (case b); and (c),(f),(i) 2014 (case c), respectively.

only surface data were available. The salinity was almost homogeneous in the vertical direction when the river discharge was low in both 2009 and 2014 (Figs. 4a,b), except for that near the river mouth. However, strong salinity stratification was formed when the river discharge reached a value larger than $3000 \mathrm{~m}^{3} \mathrm{~s}^{-1}$ (Figs. 4c,d). It remained stratified even after the river discharge decreased (Figs. $4 \mathrm{e}, \mathrm{f}$ ).

\section{b. Model results}

We performed numerical simulations to examine the mechanism for upstream extension of the Yellow River plume under the low river discharge condition in summer, as well as the transition to the downstream direction after the river discharge increased. First, we calculated the climatological salinity in the Bohai Sea (case 0), and compared it with the observations and results of the coarse grid model reported by Wang et al. (2008). The water salinity calculated by our model is closer to the observations than that calculated by the coarse grid model, especially the salinity front near the Yellow River mouth in summer. Since we used the same forcing as Wang et al. (2008), the change in model resolution is likely the reason for this improvement.

Then, we simulated the Yellow River plume in 2009 (case a), 2013 (case b), and 2014 (case c) using daily Yellow River discharges and 6-hourly wind stress data from the ECMWF in each year. The modeled surface and bottom salinity at the observational stations were compared with the observational data (Fig. S1 in the online supplemental material). As the observations were not synchronous, we compared the modeled salinity at the same hour of each CTD casting. The root-meansquare error is 3.4 for surface salinity and 1.1 for bottom salinity, respectively, and the correlation coefficient is 0.63 for surface salinity and 0.63 for bottom salinity (Fig. S1). Except for model resolution that cannot resolve the realistic bathymetry, the exact local winds over the sea and the realistic Yellow River discharge before and during observation period are actually not available. These factors strongly affect the salinity distribution near the river mouth where the salinity gradient is largest. Therefore, it is difficult for the model to reproduce the exact distribution of salinity and even a shift in spatial pattern 

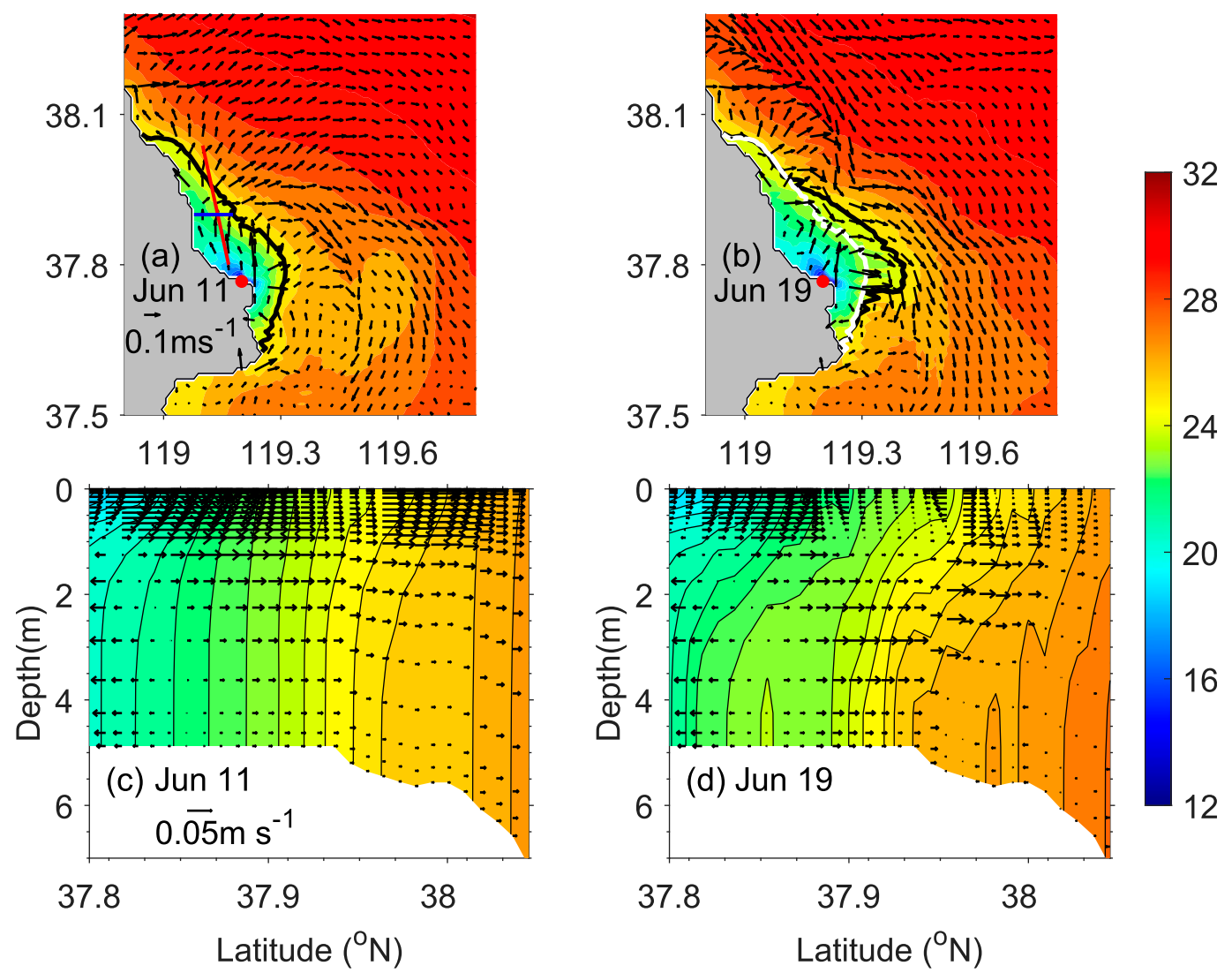

FIG. 6. (a),(b) Horizontal distributions of sea surface salinity (color) and residual current (arrow) and (c),(d) vertical distributions of salinity (color) and residual current (arrow) along the upstream section [red line in (a)] in (left) spring tide and (right) neap tide in June 2009 in case 1. The black lines in (a) and (b) show the 25 isohaline on 11 and 19 Jun, respectively, while the white line in (b) shows the 25 isohaline on 11 Jun. The red point in (a) and (b) denotes the position of the Yellow River mouth.

should also cause a large error in a direct salinity comparison between model results and observations.

However, although the specific value of modeled salinity is not perfectly consistent with the observed salinity, the distribution of the plume is consistent. The modeled lowsalinity water was distributed in the upstream direction on 19 June 2009 (Fig. 5a), symmetrically around the Yellow River mouth on 1 July (Fig. 5d), and in both upstream and downstream directions on 19 July 2009 (Fig. 5g). On 24 June 2013, as the river discharge was large $\left(2100 \mathrm{~m}^{3} \mathrm{~s}^{-1}\right)$, the plume was mainly in the upstream direction but also partially distributed in downstream direction (Fig. 5b). As the river discharge increased, the plume was distributed around the river mouth on 26 July 2013 (Fig. 5e). Although the observational station coverage was smaller in 2014, the observed pattern of low-salinity water was reproduced quite closely by the model, showing little low-salinity water in the upstream direction on 12 June (Fig. 5c), and a relatively narrow area of low-salinity water in the northeast direction on 7 July (Fig. 5f).

The model results confirm the observed low-salinity water in upstream area of the Yellow River plume under the low river discharge condition, and the transition to the downstream direction under the high river discharge condition. Consequently, the model can be used to analyze the evolution processes and dynamics between these situations and the influences of both river discharge and winds on them.

\section{Discussion}

\section{a. Reason for upstream extension of the Yellow River plume in summer}

To investigate the behavior of the Yellow River plume under the condition of low river discharge, we considered the case in 2009 as an example and designed a new case (case 1) in which the effect of wind was excluded, and only tide, heat flux, and river discharge in 2009 (black line in Fig. 2a) were considered. Except for the time when the Yellow River discharge was large from 23 June to 20 July, the low-salinity water from the Yellow River was distributed mainly in the area upstream of the river mouth in case 1 . However, the distribution of the Yellow River plume shows significant spring and neap tidal variations (Fig. 6). During spring tide (Fig. 6a), the Yellow River plume 

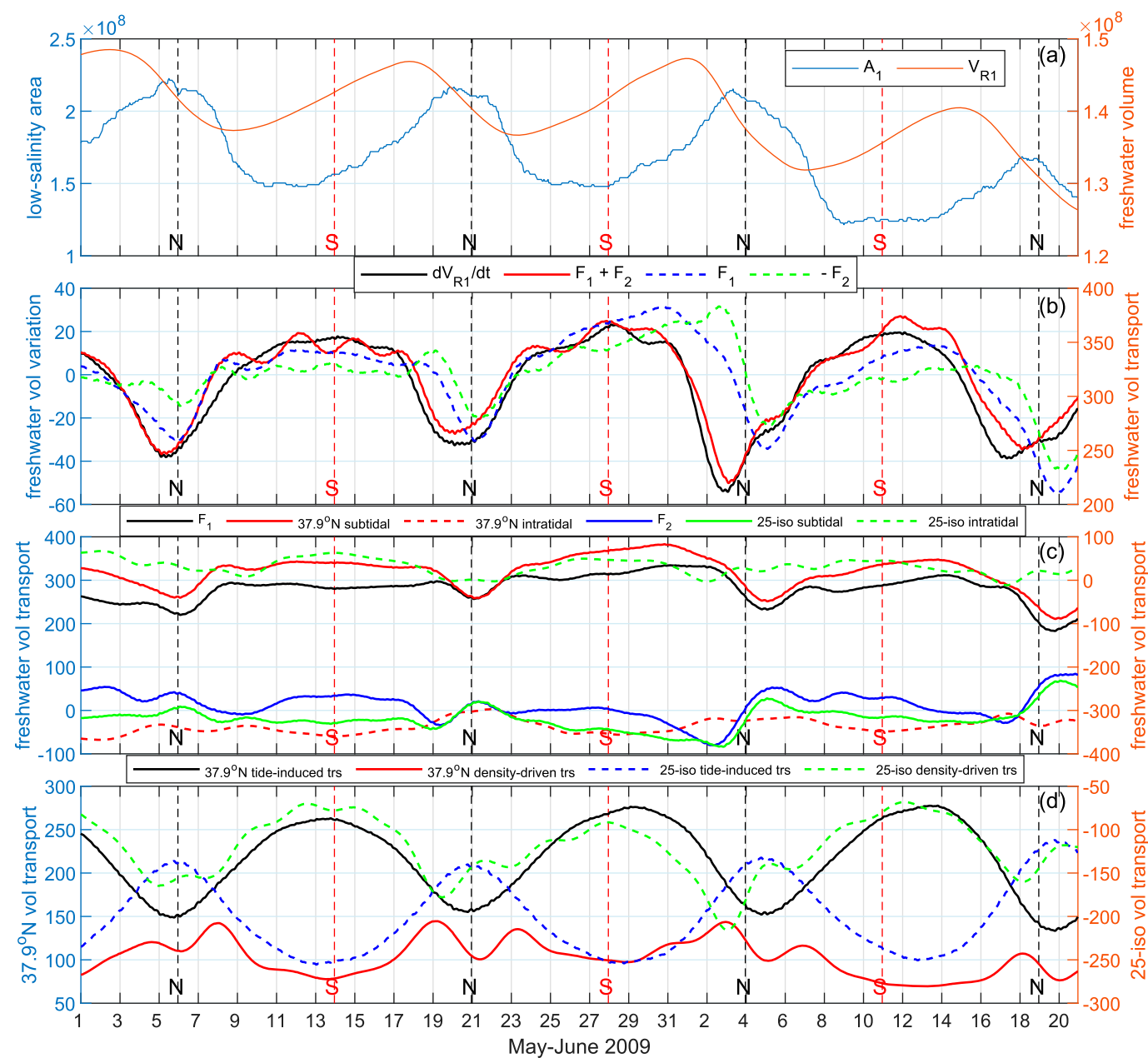

FIG. 7. (a) The low-salinity area $A_{1}\left(\mathrm{~m}^{2}\right)$ inside the 25 isohaline north of the $37.9^{\circ} \mathrm{N}$ section and the freshwater volume $V_{R 1}\left(\mathrm{~m}^{3}\right)$ inside the northern part of target domain in case 1. (b) The temporal variation rate of freshwater volume $\left(\mathrm{m}^{3} \mathrm{~s}^{-1}\right)$ inside the northern part of target domain $\left(d V_{R 1} / d t\right)$, the freshwater volume transport $\left(\mathrm{m}^{3} \mathrm{~s}^{-1}\right)$ across the $37.9^{\circ} \mathrm{N}$ section $\left(F_{1}\right)$ and northern 25 isohaline on $11 \mathrm{Jun}\left(-F_{2}\right)$, and the sum of both volume transport $\left(F_{1}+F_{2}\right)$. The $d V_{R 1} / d t$ and $F_{1}+F_{2}$ share the left axis, while $F_{1}$ and $-F_{2}$ share the right axis. (c) The freshwater volume transports $\left(\mathrm{m}^{3} \mathrm{~s}^{-1}\right)$ across the $37.9^{\circ} \mathrm{N}$ section $\left(F_{1}\right)$ and northern 25 isohaline on $11 \mathrm{Jun}\left(F_{2}\right)$, and the contributions of subtidal process and intratidal process to them. The left axis is for those across the $37.9^{\circ} \mathrm{N}$ section, and the right axis is for those across the northern 25 isohaline on 11 Jun. (d) The freshwater volume transport $\left(\mathrm{m}^{3} \mathrm{~s}^{-1}\right)$ by the tide-induced residual current and density-driven current across the $37.9^{\circ} \mathrm{N}$ section and northern 25 isohaline on 11 Jun, with the former two sharing the left axis and the latter two sharing the right axis. The black dashed lines with " $N$ " refer to the days of neap tide, while the red dashed lines with "S" refer to the days of spring tide.

(salinity $<25)$ distributes in a narrow area from river mouth to the upstream area north of the river mouth, with a northward velocity of $\sim 0.06 \mathrm{~m} \mathrm{~s}^{-1}$ inside the plume; during neap tide (Fig. 6b), it forms an anticyclonic bulge and occupies a large area from river mouth to the downstream area south of the river mouth.

The vertical distribution of salinity along a section from the river mouth to the upstream area (red line in Fig. 6a) shows that the isohalines are almost vertical to the surface in spring tide (Fig. 6c) but tilt with the surface in neap tide (Fig. 6d), which is due to the strong tidal mixing in spring tide and weak tidal mixing in neap tide. According to Yankovsky and Chapman (1997), the plume with freshwater occupying the entire water column is categorized as a bottom-advected plume, while that with lighter water distributing above the denser water is classified as a surface-advected plume. In our case, the Yellow River plume in spring tide resembles a bottom-advected plume, while that in neap tide is similar to a surface-advected plume.

The residual current along the section shows that except in the area very close to the river mouth, the current flows northward in both the surface and bottom layers in spring tide (Fig. 6c). However, in neap tide (Fig. 6d), except for the northward residual current near the river mouth, there 

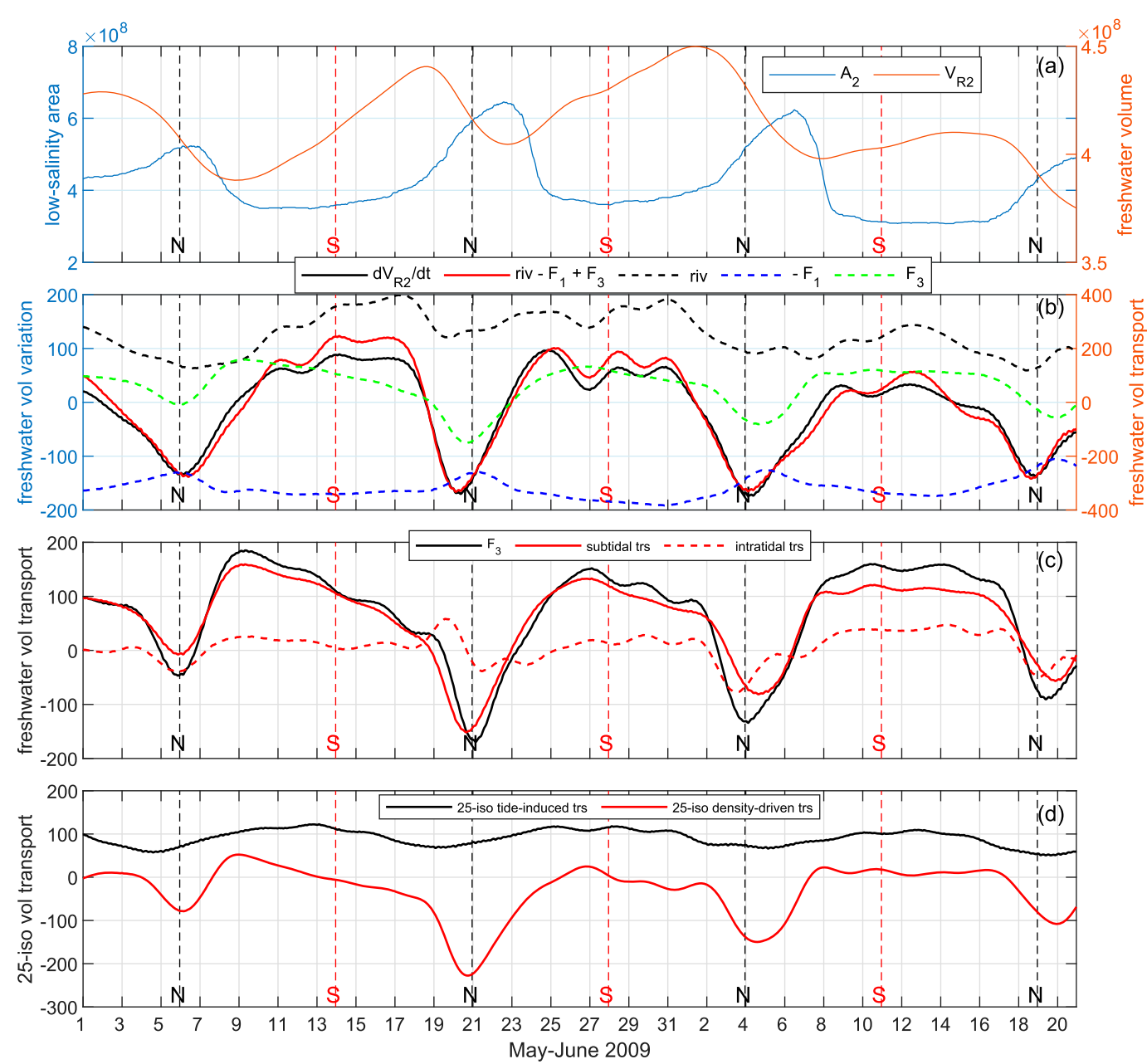

FIG. 8. (a) The low-salinity area $A_{2}\left(\mathrm{~m}^{2}\right)$ inside the 25 isohaline south of the $37.9^{\circ} \mathrm{N}$ section and the freshwater volume $V_{R 2}\left(\mathrm{~m}^{3}\right)$ inside the southern part of target domain in case 1. (b) The temporal variation rate of freshwater volume $\left(\mathrm{m}^{3} \mathrm{~s}^{-1}\right)$ inside the southern part of target domain $\left(d V_{R 2} / d t\right)$, the river discharge (riv), the northward freshwater volume transport across the $37.9^{\circ} \mathrm{N}$ section $\left(-F_{1}\right)$ and southern 25 isohaline on $11 \mathrm{Jun}\left(F_{3}\right)$, and the sum of them (riv $-F_{1}+F_{3}$ ). The $d V_{R 2} / d t$ and riv $-F_{1}+F_{3}$ share the left axis, while riv, $-F_{1}$ and $F_{3}$ share the right axis. (c) The freshwater volume transport $\left(\mathrm{m}^{3} \mathrm{~s}^{-1}\right)$ across the southern 25 isohaline on $11 \mathrm{Jun}\left(F_{3}\right)$, and the contributions of subtidal process and intratidal process to it. (d) The freshwater volume transport by the tide-induced residual current and density-driven current across the southern 25 isohaline on 11 Jun. The black dashed lines with "N" refer to the days of neap tide, while the red dashed lines with "S" refer to the days of spring tide.

is no obvious northward current in the surface layer. In particular, the surface current in the area around $37.9^{\circ} \mathrm{N}$ is southward.

We calculated the surface area of the plume with surface salinity less than 25 (Figs. 7a and 8a ). Because of the alternation in the direction of surface residual current around $37.9^{\circ} \mathrm{N}$ from spring tide to neap tide (Figs. $6 \mathrm{c}, \mathrm{d}$ ), we divide the plume into northern and southern parts by the $37.9^{\circ} \mathrm{N}$ section (blue line in Fig. 6a). In the northern part, the area $\left(A_{1}\right)$ reaches a maximum value in neap tide and a minimum value one or two days before spring tide (blue line in Fig. 7a). In the southern part, the area $\left(A_{2}\right)$ reaches a maximum value $\sim 2$ days after neap tide and a minimum value near spring tide (blue line in Fig. 8a).
To explain the variation of low-salinity area during springneap tidal cycles over the two months of calculation in case 1 , we calculate the volume of freshwater $\left(V_{R}=\overline{\iiint\left[\left(s_{0}-s\right) / s_{0}\right] d x d y d z}\right)$ inside the 25 isohaline on 11 June when the low-salinity area was at a minimum level in both the northern and southern parts (Figs. 7a and 8a). Being the same as the area, we also divide this fixed target domain into two parts by the $37.9^{\circ} \mathrm{N}$ section. In the equation for $V_{R}, s_{0}$ is a background salinity with a value of $32, s$ is the salinity at each grid point inside the target domain, the integration in the $x$ direction is from the coastline to the 25 isohaline, the integration in the $y$ direction is from the $37.9^{\circ} \mathrm{N}$ section to the 25 isohaline in the northern area and from the 25 isohaline to the $37.9^{\circ} \mathrm{N}$ section in the southern area, respectively, and the integration in the $z$ 
direction is from the sea bottom to the sea surface. The overbar denotes the detiding procedure using a low-pass filter (Hanawa and Mitsudera 1985).

The $V_{R}$ in the northern part of the target domain $\left(V_{R 1}\right.$, orange line in Fig. 7a) increases from neap tide to spring tide, reaches a maximum value after spring tide, decreases toward neap tide, and reaches a minimum value after neap tide. As comparing the two lines in Fig. 7a, we found a time lag of 3-4 days between the peak values of freshwater volume in the northern part of target domain $V_{R 1}$ and the area with a surface salinity less than 25 north of $37.9^{\circ} \mathrm{N}$ section $\left(A_{1}\right.$, blue line in Fig. 7a). In addition, as passing each spring tide toward next neap tide, both $V_{R 1}$ and $A_{1}$ increase, showing an in-phase variation. There is also a short time for both $V_{R 1}$ and $A_{1}$ to decrease. Apparently, the horizontal transport of freshwater through the fixed lateral boundary defined by the 25 isohaline on 11 June (Fig. 6a) is a key process to understand the relation between $V_{R 1}$ and $A_{1}$ as well as the temporal change of $A_{1}$.

The temporal variation rate of $V_{R 1}$ (black line in Fig. 7b) is approximately determined by the horizontal transport of freshwater through the $37.9^{\circ} \mathrm{N}$ section and the northern 25 isohaline on 11 June. This relation is expressed as following equation:

$$
\frac{d V_{R 1}}{d t}=F_{1}(t)+F_{2}(t)+\mathrm{HDIF}_{1}
$$

where $\quad F_{1}(t)=\overline{\iint\left[\left(s_{0}-s\right) / s_{0}\right] v d x d z}$ and $\quad F_{2}(t)=$ $\overline{\iint\left[\left(s_{0}-s\right) / s_{0}\right] u(v) d y(d x) d z}$ are the freshwater volume transport across the $37.9^{\circ} \mathrm{N}$ section and the northern 25 isohaline on 11 June, respectively, $\mathrm{HDIF}_{1}$ is the freshwater volume transport across the $37.9^{\circ} \mathrm{N}$ section and the northern 25 isohaline caused by horizontal diffusion. In this calculation, the 25 isohaline on 11 June is represented by a steplike line composed by some meridional and zonal grid lines. If the line at a grid point is at meridional direction, the freshwater volume transport at that grid point is given by $\iint\left[\left(s_{0}-s\right) / s_{0}\right] u d y d z$; if the line is at zonal direction, it is by $\iint\left[\left(s_{0}-s\right) / s_{0}\right] v d x d z$.

The $d V_{R 1} / d t$ is positive $\left(20 \mathrm{~m}^{3} \mathrm{~s}^{-1}\right)$ around spring tide and negative $\left(-30 \mathrm{~m}^{3} \mathrm{~s}^{-1}\right)$ near neap tide (black line in Fig. $7 \mathrm{~b}$ ). The positive value has a longer duration than negative value, indicating a slow increasing but fast decreasing of freshwater volume inside the target domain. The freshwater transport through the $37.9^{\circ} \mathrm{N}\left(F_{1}\right)$ is persistently northward (blue dashed line in Fig. 7b, acting as an influx of freshwater), and that through the northern 25 isohaline of 11 June $\left(F_{2}\right)$ is persistently outward $\left(-F_{2}\right.$ by the green dashed line in Fig. 7b, acting as an outflux of freshwater). Both values of transport are larger in spring tide than in neap tide. Around spring tide, the former is larger than the latter, thus, the freshwater volume inside the northern area increases; $\sim 3$ days before neap tide, the former becomes smaller than the latter, thus, the freshwater volume inside the northern area becomes to decrease. Therefore, the freshwater volume inside the northern area reaches the peak value $\sim 3$ days before neap tide (orange line in Fig. 7a). It must be noted that the sum of $F_{1}$ and $F_{2}$ is close to $d V_{R 1} / d t$ in Fig. 7b, indicating the negligible role of horizontal diffusion $\mathrm{HDIF}_{1}$ on lateral transport of freshwater.

In the southern part of the target domain, the freshwater volume $V_{R 2}$ also starts increasing after neap tide, keeps increasing after spring tide; after reaching a maximum value before next neap tide, it starts decreasing and reaches a minimum value after next neap tide (orange line in Fig. 8a). There is also a time lag of $\sim 4$ days between the peak values of the lowsalinity water area south of the $37.9^{\circ} \mathrm{N}$ section and the freshwater volume in the southern part of target domain (Fig. 8a). Their in-phase and antiphase variations as well as their time lag indicate a close relation between them.

Being similar to the northern part of target domain, the temporal variation of freshwater volume $V_{R 2}$ can be expressed by the budget of the horizontal transports of freshwater through the $37.9^{\circ} \mathrm{N}$ section and the southern 25 isohaline on 11 June, and the direct input of river water through the equation

$$
\frac{d V_{R 2}}{d t}=\operatorname{riv}-F_{1}(t)+F_{3}(t)+\mathrm{HDIF}_{2},
$$

where riv, $F_{1}(t)$, and $F_{3}(t)$ are the river discharge, northward freshwater transport across the $37.9^{\circ} \mathrm{N}$ section, and the horizontal freshwater transport across the southern 25 isohaline on 11 June, respectively; $\mathrm{HDIF}_{2}$ is the freshwater volume transport across the $37.9^{\circ} \mathrm{N}$ section and the southern 25 isohaline caused by horizontal diffusion.

The $d V_{R 2} / d t$ is positive $\left(100 \mathrm{~m}^{3} \mathrm{~s}^{-1}\right)$ around spring tide and negative $\left(-170 \mathrm{~m}^{3} \mathrm{~s}^{-1}\right)$ near neap tide (black line in Fig. $\left.8 b\right)$. Again the duration is longer for positive values than for negative values. The river discharge ranges from 100 to $400 \mathrm{~m}^{3} \mathrm{~s}^{-1}$ and naturally has no spring-neap tidal cycle (black dashed line in Fig. 8b). The freshwater transport across the southern 25 isohaline on 11 June $\left(F_{3}\right)$ is positive around spring tide $\left(100 \mathrm{~m}^{3} \mathrm{~s}^{-1}\right)$ but negative near neap tide $\left(-150 \mathrm{~m}^{3} \mathrm{~s}^{-1}\right)$ (green dashed line in Fig. $8 \mathrm{~b}$ ). The sum of riv, $-F_{1}$, and $F_{3}$ is positive around spring tide and negative around neap tide (red line in Fig. 8b), coinciding well with $d V_{R 2} / d t$ and demonstrating again the negligible role of horizontal diffusion on freshwater transport.

From above analysis, we found that the freshwater transport across the $37.9^{\circ} \mathrm{N}$ section is an essential factor for keeping the low-salinity water in the northern area. In the southern area, the lateral transport of freshwater across the 25 isohaline on 11 June is a key process for the expanding or shrinking of lowsalinity water area on the other days. For example, as the outward freshwater transport across the 25 isohaline on 11 June (green dashed line in Fig. 8b) increases from two days before neap tide, the low-salinity water area in the southern area $\left(A_{2}\right.$, blue line in Fig. 8a) also increases. When the former decreases and approaches zero 2 days after neap tide (green dashed line in Fig. 8b), the latter reaches the maximum value (blue line in Fig. 8a). When the freshwater transport across the 25 isohaline on 11 June becomes positive (inward, green dashed line in Fig. $8 \mathrm{~b}$ ), the area $\left(A_{2}\right)$ decreases sharply (blue line in Fig. 8a).

To clarify the processes responsible for the freshwater volume transport across the $37.9^{\circ} \mathrm{N}$ section and the 25 isohalines 
on 11 June, we divide the transport into the subtidal process and intratidal process. The salinity $s$ and velocity $v$ are subsequently divided into two parts: one is the subtidal component $(\bar{s}, \bar{v})$, and the other is the anomaly $\left(s^{\prime}, v^{\prime}\right)$. Following this decomposition, the freshwater volume transport is given as

$$
\overline{\iint \frac{s_{0}-s}{s_{0}} v d x d z}=\iint \frac{s_{0}-\bar{s}}{s_{0}} \bar{v} d x d z-\overline{\iint \frac{s^{\prime} v^{\prime}}{s_{0}} d x d z}
$$

The first term on the right-hand side of Eq. (3) denotes the transport contributed by the subtidal process, and the second term by the intratidal process.

The freshwater transport across the $37.9^{\circ} \mathrm{N}$ section $\left(F_{1}\right)$ is mainly attributed to the subtidal process (red line in Fig. $7 \mathrm{c}$ ), whose value is $\sim 400 \mathrm{~m}^{3} \mathrm{~s}^{-1}$ in spring tide and $\sim 250 \mathrm{~m}^{3} \mathrm{~s}^{-1}$ in neap tide and shows a similar spring-neap tidal variation as $F_{1}$. The freshwater transport by the intratidal process (red dashed line in Fig. 7c) shows a small negative value $\left(-50 \mathrm{~m}^{3} \mathrm{~s}^{-1}\right)$ with a slight temporal variation. This feature is also true for the freshwater transport through the northern 25 isohaline on 11 June $\left(F_{2}, \sim-300 \mathrm{~m}^{3} \mathrm{~s}^{-1}\right.$, blue line in Fig. 7c), which is mainly contributed by the subtidal process $\left(-300 \mathrm{~m}^{3} \mathrm{~s}^{-1}\right.$, green line in Fig. 7c) because the transport by the intratidal process is much smaller $\left(50 \mathrm{~m}^{3} \mathrm{~s}^{-1}\right.$, green dashed line in Fig. 7c). The freshwater transport through the southern 25 isohaline on 11 June ( $F_{3}$, black line in Fig. $\left.8 \mathrm{c}\right)$ is also attributed to the subtidal process (red line in Fig. 8c) because the transport by the intratidal process (red dashed line in Fig. 8c) is small. Because the salinity field has only slight change during a spring-neap tidal cycle, the subtidal current is likely the reason for the different freshwater transport in spring and neap tides.

An apparent spring-neap tidal cycle in the subtidal current prompts us to examine the tide-induced residual current by running the model forced only by tide (case 2 ). The cotide map (Figs. 9a,b) and tidal ellipse (Figs. 9c,d) given by the model results are consistent with those in previous studies (Dou et al. 1981; Fang and Yang 1985; Fang 1986). The tide near the Yellow River mouth is dominated by $\mathrm{M}_{2}$ and $\mathrm{K}_{1}$ whose combination forms an irregular semidiurnal tide. The tidal current near the Yellow River mouth is rectilinear, which flows southward during flood and northward during ebb (Fig. 9c). The tide-induced residual current near the Yellow River mouth flows northward, and its maximum speed is $\sim 0.07 \mathrm{~m} \mathrm{~s}^{-1}$ in spring tide (Fig. $9 \mathrm{e}$ ) and $\sim 0.02 \mathrm{~m} \mathrm{~s}^{-1}$ in neap tide (Fig. 9f). This northward tide-induced residual current near the Yellow River mouth has been reported in many previous studies (Dou et al. 1981; Fang and Yang 1985; Zhao et al. 1995; Huang et al. 1999; Wei et al. 2004). In addition, Zhao et al. (1995) and Wei et al. (2004) observed that the sediment from the Yellow River was transported northward, and attributed this northward transport of sediment to the northward tide-induced residual current near the Yellow River mouth.

As an approximation of the density-driven current, we calculate the difference in residual current between case 1 and case 2 . In the surface layer, the density-driven current
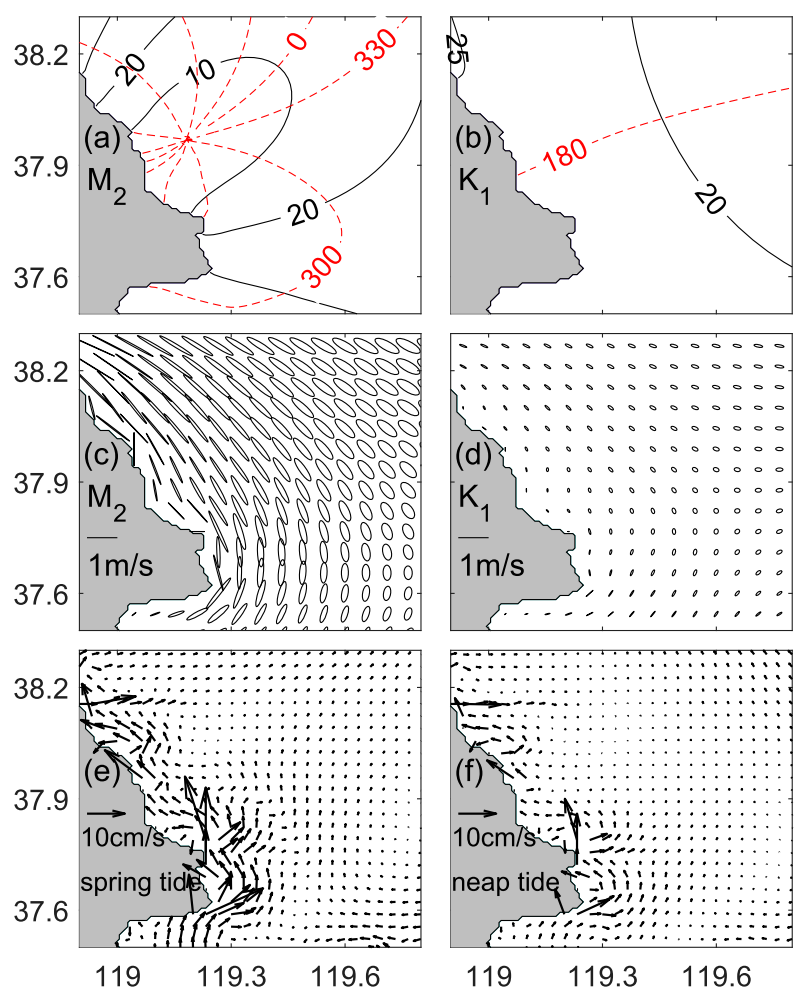

FIG. 9. (a),(b) Cotide map and (c),(d) tidal ellipse of $\mathrm{M}_{2}$ and $\mathrm{K}_{1}$ tide constituent off the Yellow River mouth, and the horizontal distribution of tide-induced residual current in (e) spring tide and (f) neap tide. In (a) and (b), the black solid lines denote the amplitude $(\mathrm{cm})$ and the red dashed lines show the phase.

inside the plume flows northward from the river mouth and then turns southward in both spring tide and neap tide (Figs. 10a,b). Furthermore, the current is stronger in neap tide (Fig. 10b) than in spring tide (Fig. 10a). At the $37.9^{\circ} \mathrm{N}$ section where we examined the freshwater transport, the density-driven current is southward in the surface layer and northward in the bottom layer (Figs. 10c,d). Both the surface southward current and the bottom northward current are stronger in neap tide (Fig. 10d) than in spring tide (Fig. 10c). For example, the surface southward current is $0.01 \mathrm{~m} \mathrm{~s}^{-1}$ in spring tide and $0.05 \mathrm{~m} \mathrm{~s}^{-1}$ in neap tide. In both the estuary (Wong 1994) and the offshore shelf area (Kasai et al. 2000), the density-driven current is inversely correlated to the vertical eddy viscosity, which is stronger in spring tide than in neap tide.

The northward tide-induced residual current is stronger in spring tide than in neap tide (Figs. 9e,f). The southward surface density-driven current is stronger in neap tide than in spring tide (Figs. 10a,b). To quantify their contribution to freshwater transport, we use the same method as those in Eqs. (1) and (2) to calculate the freshwater transport across the three sections by the tide-induced residual current and density-driven current, respectively. At the $37.9^{\circ} \mathrm{N}$ section, the freshwater transport by the tide-induced residual current 

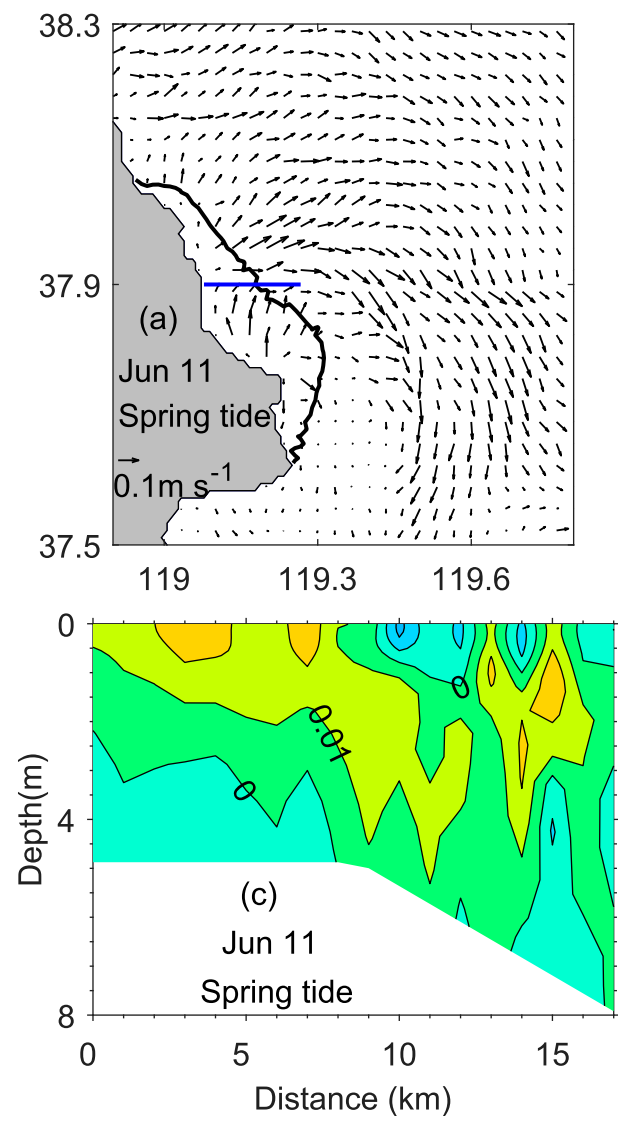
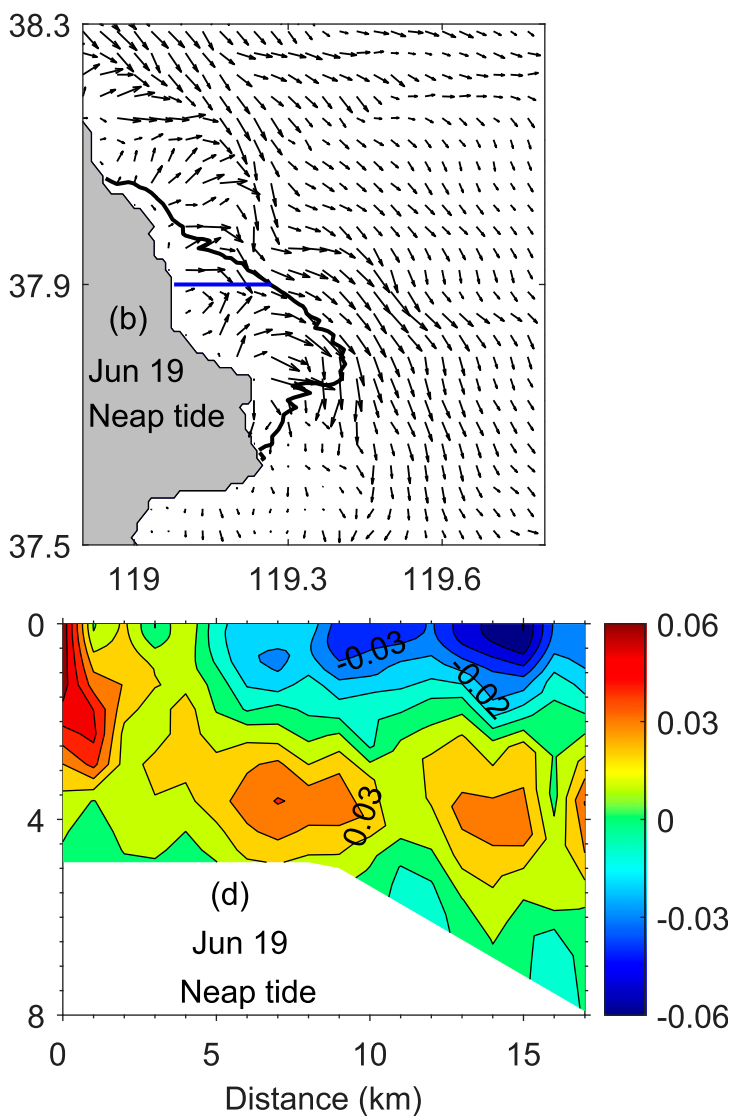

FIG. 10. Horizontal distribution of surface density-driven current, which is approximated by the difference of residual currents between case 1 and case 2 on (a) 11 Jun and (b) 19 Jun. Vertical distribution of northward densitydriven current across the section denoted by the blue line in (a) and (b) on (c) 11 Jun and (d) 19 Jun. The black line in (a) and (b) shows the 25 isohaline of the bulge in case 1.

shows apparent spring tide $\left(270 \mathrm{~m}^{3} \mathrm{~s}^{-1}\right)$ and neap tidal variations $\left(150 \mathrm{~m}^{3} \mathrm{~s}^{-1}\right)$ (black line in Fig. $\left.7 \mathrm{~d}\right)$, and is stronger than that by the density-driven current $\left(\sim 100 \mathrm{~m}^{3} \mathrm{~s}^{-1}\right)$ (red line in Fig. 7d). At the northern 25-isohaline on 11 June, the outward freshwater transport by the tide-induced residual current $\left(-250 \mathrm{~m}^{3} \mathrm{~s}^{-1}\right.$, blue dashed line in Fig. $\left.7 \mathrm{~d}\right)$ is stronger than that by the density-driven current $\left(-100 \mathrm{~m}^{3} \mathrm{~s}^{-1}\right.$, green dashed line in Fig. 7d) in spring tide, but is smaller $\left(-150 \mathrm{~m}^{3} \mathrm{~s}^{-1}\right)$ than that $\left(-200 \mathrm{~m}^{3} \mathrm{~s}^{-1}\right)$ in neap tide. At the southern 25 isohaline on 11 June, the freshwater transport by the tide-induced residual current is always positive $\left(\sim 100 \mathrm{~m}^{3} \mathrm{~s}^{-1}\right.$, black line in Fig. $\left.8 \mathrm{~d}\right)$, showing a slight springneap tidal variation, while that by the density-driven current is generally negative, showing a relatively larger springneap tidal variation (red line in Fig. 8d). Consequently, the freshwater transport across the $37.9^{\circ} \mathrm{N}$ section is likely dominated by the tide-induced residual current, while that across the 25 isohaline is controlled by tide-induced residual current in spring tide and by density-driven current in neap tide. For this reason, we suggest that the upstream extension of the plume is promoted by the upstream tide-induced residual current around the river mouth in spring tide, while the downstream extension is attributed to the downstream density-driven current around the offshore plume front in neap tide.

The above consideration on the fortnightly variations of tide-induced residual current and density-driven current needs supports from a viewpoint of momentum balance, in which the advection term is necessary for the tide-induced residual current while the vertical eddy viscosity term is necessary for the density-driven current. We then calculate the momentum equation for the surface northward velocity using Eq. (4):

$$
\overline{\frac{\partial v}{\partial t}}=\overline{\operatorname{adv}}+\overline{\operatorname{cor}}+\overline{\text { pre }}+\overline{\text { vert_vis }}+\overline{\text { hori_vis }} .
$$

In Eq. (4), $v$ is the northward component of the velocity, adv is the advection term, cor is the Coriolis force, pre is the pressure gradient term, vert_vis is the vertical eddy viscosity term, and hori_vis is the horizontal eddy viscosity term. The overbar above each term denotes detiding procedure by a lowpass filter (Hanawa and Mitsudera 1985).

In spring tide, the advection term in the north area of the river mouth (Fig. 11a) is positive, which is favorable to the acceleration of the northward current, whereas the Coriolis 

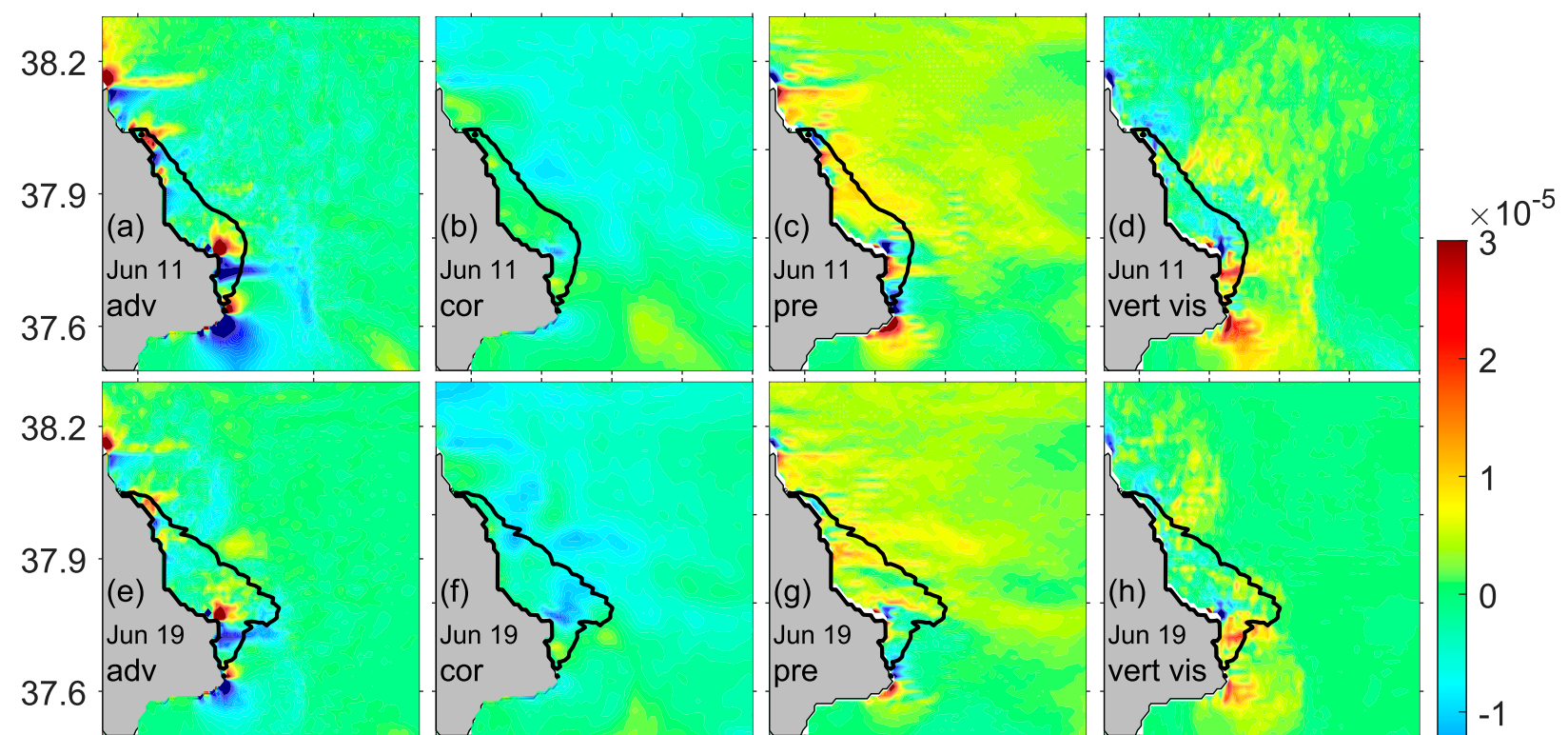

38.2
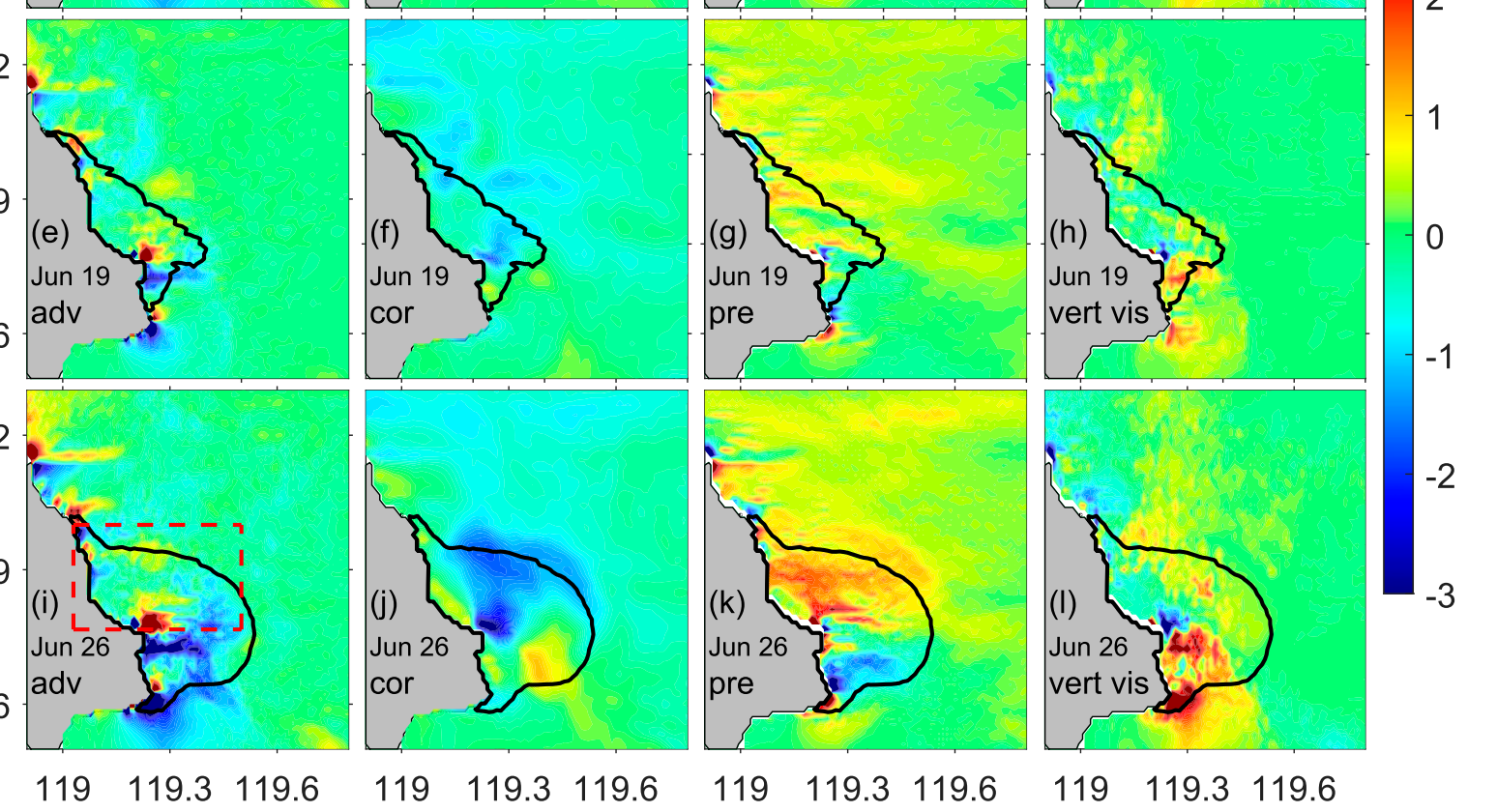

FIG. 11. Horizontal distribution of the (a),(e),(i) advection term; (b),(f),(j) Coriolis force; (c),(g),(k) pressure gradient term; and (d),(h),(1) vertical viscosity term in the momentum equation [Eq. (4)] for the northward component of velocity on (top) 11 Jun (spring tide, $154 \mathrm{~m}^{3} \mathrm{~s}^{-1}$ ), (middle) $19 \mathrm{Jun}$ (neap tide, $173 \mathrm{~m}^{3} \mathrm{~s}^{-1}$ ), and (bottom) $26 \mathrm{Jun}$ (spring tide, $3250 \mathrm{~m}^{3} \mathrm{~s}^{-1}$ ) in case 1 . The units of all the values are $\mathrm{m} \mathrm{s}^{-2}$. The black line in each panel shows the 25 isohaline of the plume. The red rectangle in (i) shows the area where averaged surface momentum terms are calculated inside the plume in Fig. 12.

force is relatively small inside the plume (salinity smaller than 25) (Fig. 11b). The advection term inside the plume is balanced by the pressure gradient term (Fig. 11c) and vertical eddy viscosity term (Fig. 11d). In neap tide, the Coriolis force becomes negative inside the plume (Fig. 11f), and is likely balanced by the pressure gradient term (Fig. 11g) and vertical eddy viscosity term (Fig. 11h).

To quantitatively evaluate the change of these terms within the spring-neap tidal cycle, we spatially average the surface momentum terms in an area north of the Yellow River mouth (the red rectangle in Fig. 11i). The time series shows significant spring-neap tidal variations in the advection term, Coriolis force, and vertical eddy viscosity term before 19 June when the Yellow River discharge was small (Fig. 12). The advection term (red solid line in Fig. 12) is positive $\left(0.4 \times 10^{-5} \mathrm{~m} \mathrm{~s}^{-2}\right)$ around spring tide but decreases to a negative value $(-0.1 \times$ $10^{-5} \mathrm{~m} \mathrm{~s}^{-2}$ ) in neap tide. The vertical eddy viscosity term (red dashed line in Fig. 12) is negative $\left(-0.4 \times 10^{-5} \mathrm{~m} \mathrm{~s}^{-2}\right)$ in spring tide but positive $\left(0.4 \times 10^{-5} \mathrm{~m} \mathrm{~s}^{-2}\right)$ in neap tide, acting to decelerate both the northward residual current in spring tide and the southward residual current in neap tide. The pressure gradient (blue solid line in Fig. 12) is always positive and shows little fortnightly variation. The Coriolis force (blue dashed line in Fig. 12) is always negative but shows a large fortnightly variation $\left(-0.9 \times 10^{-5} \mathrm{~m} \mathrm{~s}^{-2}\right.$ in neap tide and $-0.2 \times 10^{-5} \mathrm{~m} \mathrm{~s}^{-2}$ in spring tide).

The combination of above four terms is positive in spring tide but negative in neap tide (black line in Fig. 12), indicating an acceleration of a northward current in spring tide and that of a southward current in neap tide. The magnitude of advection term and its fortnightly variation indicate an acceleration of the northward current in spring tide and its deceleration in neap tide, which confirms our interpretation of the tide-induced residual current. The magnitude of vertical eddy viscosity term demonstrates its important role in momentum balance, supporting our interpretation on the inverse correlation of density-driven current with vertical eddy viscosity. 


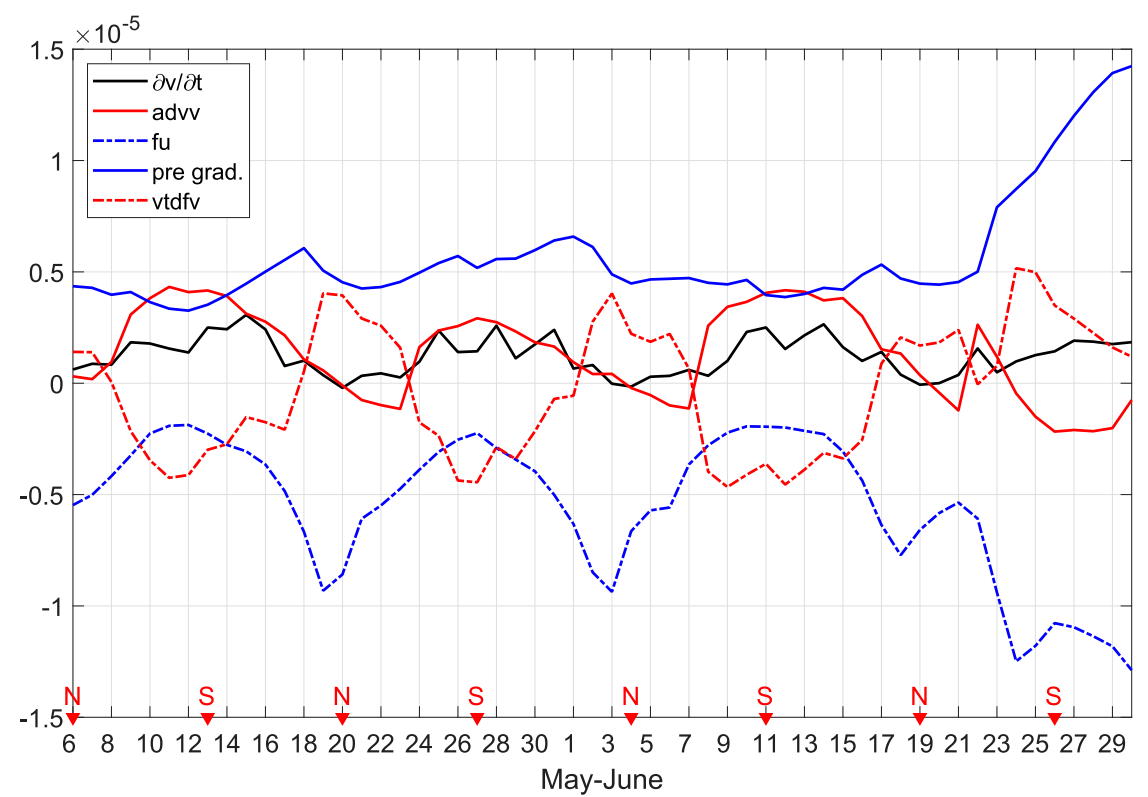

FIG. 12. Time series of surface momentum terms $\left(\mathrm{m} \mathrm{s}^{-2}\right)$ averaged inside the bulge to the north of the Yellow River mouth (within the red rectangle in Fig. 11i) in May and June 2009 in case 1 . The red triangles with "N" refer to the days of neap tide, while those with "S" refer to the days of spring tide.

\section{b. Transition to downstream extension under high river discharge}

As mentioned in section 3, both the observations and model results showed that the low-salinity water from the Yellow River was mainly concentrated in the upstream area when the river discharge was low, but turned to downstream area when the river discharge increased in all three years $(2009,2013$, and 2014). To investigate the reason for the transition of the lowsalinity water from the upstream area to the downstream area, we consider case 1 in 2009 to examine the dynamics responsible for different movement directions under different river discharges in spring tide. The days of spring tide (and corresponding river discharge) are 11 June $\left(154 \mathrm{~m}^{3} \mathrm{~s}^{-1}\right), 26$ June $\left(3250 \mathrm{~m}^{3} \mathrm{~s}^{-1}\right), 11$ July $\left(338 \mathrm{~m}^{3} \mathrm{~s}^{-1}\right)$, and 25 July $\left(543 \mathrm{~m}^{3} \mathrm{~s}^{-1}\right)$, from which 11 June and 26 June are chosen for a comparison of low river discharge and high river discharge.

The Yellow River plume shows significantly different patterns under different river discharges in spring tide, which propagates upstream on 11 June (Fig. 13a), but forms a large anticyclonic bulge near the river mouth on 26 June (Fig. 13b). The vertical distribution of salinity also exhibits different characteristics, which is vertically homogeneous on 11 June (Fig. 13c), but strongly stratified on 26 June (Fig. 13d). Garvine (1995) suggested that for a small-scale plume, advection was stronger than the Coriolis force, while for a large-scale plume, Coriolis force was stronger than the advection. The relative importance of the advection term for the small-scale plume on 11 June has been verified in section $4 \mathrm{a}$, whereas the relative importance of the Coriolis force for the large-scale plume on 26 June needs to be confirmed.
Following Eq. (4), we also calculated the momentum balance in the same spring tide but for different river discharges. The results under low river discharge condition have been presented in Figs. 11a-d and described in section 4a. The results under high river discharge condition are presented in Figs. 11i-1. Under the low river discharge condition on 11 June, the advection term (Fig. 11a) and pressure gradient term (Fig. 11c) are larger than the Coriolis force (Fig. 11b). However, the situation changes on 26 June, when the Coriolis force and pressure gradient terms (Figs. 11j,k) are much larger than the advection term (Fig. 11i). The time series of the surface momentum terms averaged in the area north of the river mouth also show that the advection term $\left(-0.2 \times 10^{-5} \mathrm{~m} \mathrm{~s}^{-2}\right)$ and vertical eddy viscosity term $\left(0.3 \times 10^{-5} \mathrm{~ms}^{-2}\right)$ were smaller than the Coriolis force $\left(-1.1 \times 10^{-5} \mathrm{~m} \mathrm{~s}^{-2}\right)$ and pressure gradient term $\left(1.1 \times 10^{-5} \mathrm{~m} \mathrm{~s}^{-2}\right)$ on 26 June (Fig. 12), which means that the Yellow River plume in the high river discharge condition is controlled mainly by a geostrophic balance.

The plume extension directions under different river discharge conditions are further examined from the idealized numerical model. We calculate the volume of freshwater $V_{R}$ in the upstream area by dividing the model domain into two parts using the section denoted by the dashed line in Fig. 14a. The ratio of $V_{R}$ in the upstream area to that in the entire domain is calculated for all the sensitivity experiments (Figs. 14b,c). In the situation with a tidal current amplitude of $0.1 \mathrm{~m} \mathrm{~s}^{-1}$ (Fig. 14b), this ratio is smaller than $22.5 \%$ under the southward downstream ambient current, and decreases synchronously with the increasing of downstream ambient current (from 0 to $-0.05 \mathrm{~m} \mathrm{~s}^{-1}$ ). Under the northward upstream 

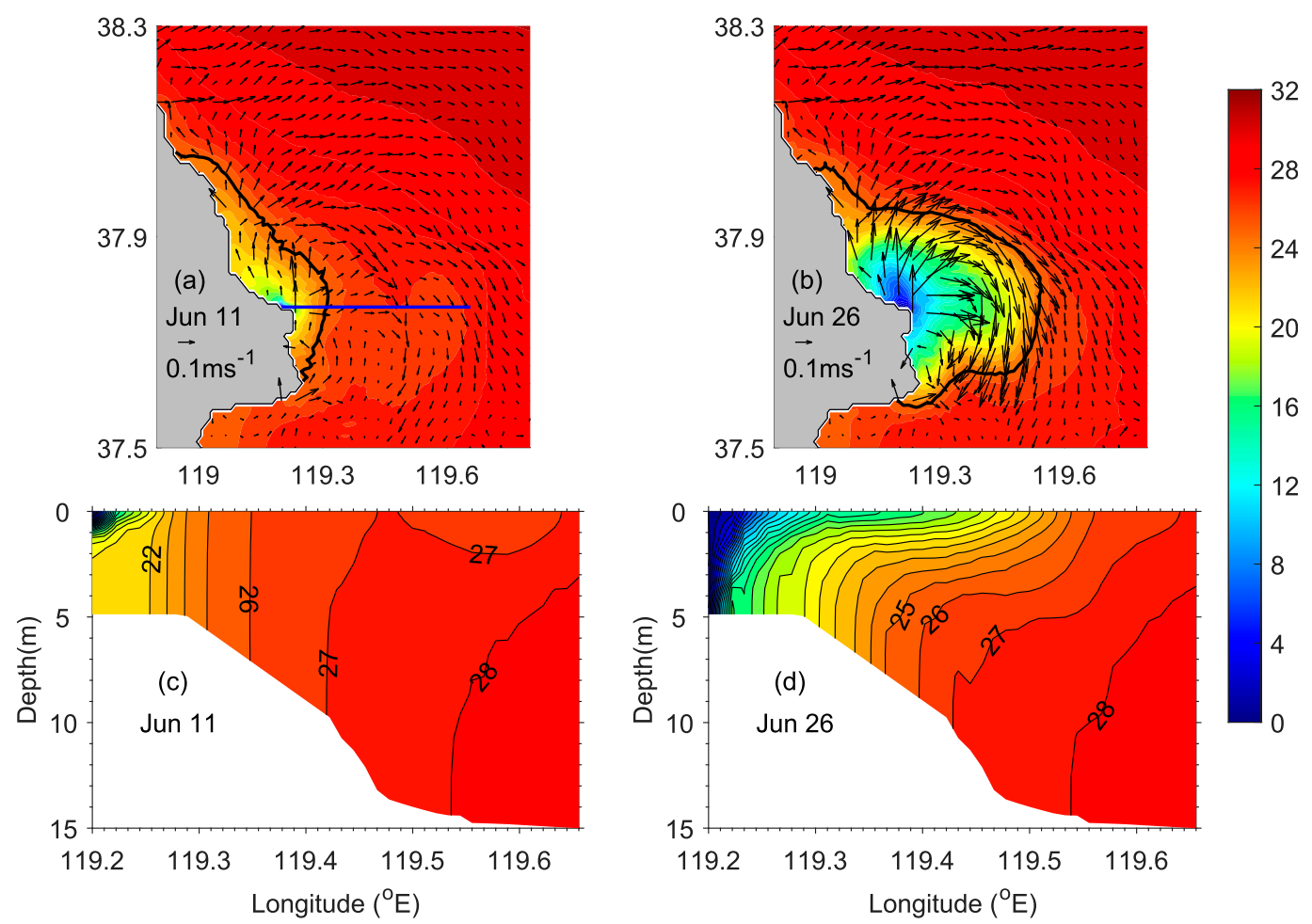

FIG. 13. (a),(b) Horizontal distribution of salinity (color) and residual current (arrow) and (c),(d) vertical distribution of salinity along the section denoted by the blue line in (a) on (left) 11 Jun and (right) 26 Jun in case 1. The black line in (a) and (b) shows the 25 isohaline of the bulge.

ambient current, this value increases with the speed of ambient current $\left(0-0.1 \mathrm{~m} \mathrm{~s}^{-1}\right)$, but is also dependent on river discharge. For example, under the ambient current of $0.1 \mathrm{~m} \mathrm{~s}^{-1}$, it is $75 \%$ for the river discharge of $100 \mathrm{~m}^{3} \mathrm{~s}^{-1}$, but becomes $50 \%$ for the river discharge of $3000 \mathrm{~m}^{3} \mathrm{~s}^{-1}$.

To define the upstream extension of plume, we specify a critical value of $50 \%$ that means half of freshwater distributing in the upstream area. According to Fig. 14b, the river discharge and the speed of upstream ambient current are closely linked for the alternation of upstream and downstream extension of the plume. There is a critical river discharge for a specific ambient current. For example, the critical river discharge is $3000 \mathrm{~m}^{3} \mathrm{~s}^{-1}$ for an upstream ambient current of $0.1 \mathrm{~m} \mathrm{~s}^{-1}$. Under such ambient current $\left(0.1 \mathrm{~m} \mathrm{~s}^{-1}\right)$, the river plume will turn upstream with a river discharge $R$ less than the critical river discharge $\left(R<3000 \mathrm{~m}^{3} \mathrm{~s}^{-1}\right)$, but turn downstream if the river discharge is larger than the critical river discharge $(R>$ $3000 \mathrm{~m}^{3} \mathrm{~s}^{-1}$ ).

As the tidal current amplitude increases to $1 \mathrm{~m} \mathrm{~s}^{-1}$ (Fig. 14c), the relation between the river discharge and the speed of upstream ambient current is kept for the upstream extension of the plume. However, as compared to Fig. 14b, under the same ambient current (e.g., $0.1 \mathrm{~m} \mathrm{~s}^{-1}$ ), the critical river discharge that turns the river plume downstream decreases $\left(2500 \mathrm{~m}^{3} \mathrm{~s}^{-1}\right)$. Therefore, a strong tidal current is favorable to the downstream movement of rive plume due to strong tidal mixing, which is consistent with previous reports (Isobe 2005).
According to these experiments, we want to find a threshold river discharge that changes the plume direction from upstream to downstream under a specified upstream ambient current. Following the idea in Whitney and Garvine (2005) who considered the competition between a buoyancy driven current and a wind-driven current, we define a dimensionless number $W_{d}=V_{\text {dis }} / V_{\text {amb }}$ to consider the competition between the buoyancy driven current $V_{\text {dis }}$ and the upstream ambient current $V_{\text {amb. }}$.

The buoyancy driven current corresponding to a specified river discharge are calculated by $V_{\text {dis }}=(1 / K)\left(2 g_{r}^{\prime} Q f\right)^{1 / 4}$ (Whitney and Garvine 2005), in which $K$ is the internal Kelvin number $\left(K=L_{y} / R\right), g_{r}^{\prime}$ is the reduced gravity of river water $\left(g_{r}^{\prime}=g \Delta \rho_{r} / \rho_{a}\right.$, where $\Delta \rho_{r}=\rho_{a}-\rho_{r}, \rho_{a}$ is the ambient density outside the plume, $\rho_{r}$ is the density of river water), $Q$ is the river discharge, and $f$ is the Coriolis parameter. Also, $L_{y}$ is the across-shore width of plume, $R\left(R=\sqrt{g^{\prime} h} / f\right)$ is the internal Rossby radius, $g^{\prime}$ is the reduced gravities of buoyant outflow ( $g^{\prime}=g \Delta \rho / \rho_{a}$, where $\Delta \rho=\rho_{a}-\rho, \rho$ is the density inside the plume), and $h$ is the plume depth. These parameters are derived from the idealized model result on the 25 th day. For example, when the river discharge is $1000 \mathrm{~m}^{3} \mathrm{~s}^{-1}$ and the amplitude of tidal current is $0.1 \mathrm{~ms}^{-1}, L_{y}$ is $23543 \mathrm{~m}, g^{\prime}$ is $0.152 \mathrm{~m} \mathrm{~s}^{-2}, h$ is $5.8 \mathrm{~m}, R$ is $10558 \mathrm{~m}, g_{r}^{\prime}$ is $0.239 \mathrm{~m} \mathrm{~s}^{-2}$, and thus $V_{\text {dis }}$ is $0.20 \mathrm{~m} \mathrm{~s}^{-1}$.

For a specific river discharge, the plume can extend upstream or downstream under different ambient currents. We 
(a) Model domain

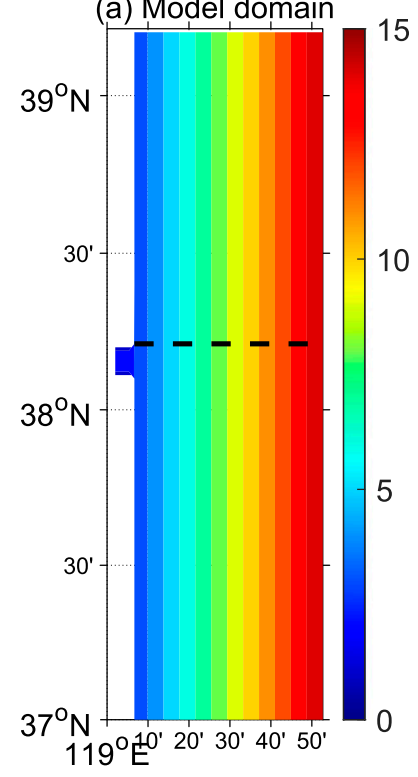

(b) Tidal amplitude $=0.1 \mathrm{~m} / \mathrm{s}$

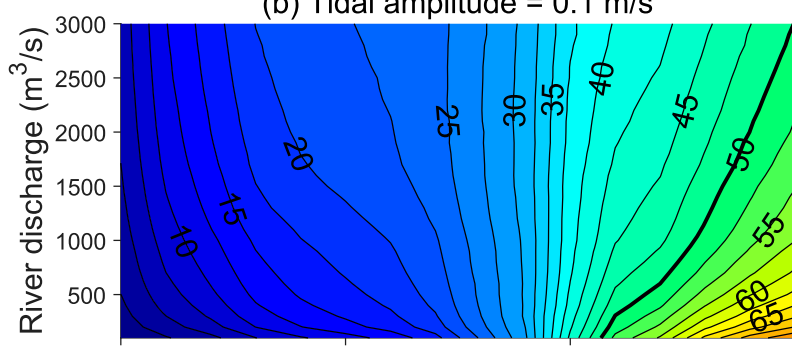

(c) Tidal amplitude $=1 \mathrm{~m} / \mathrm{s}$

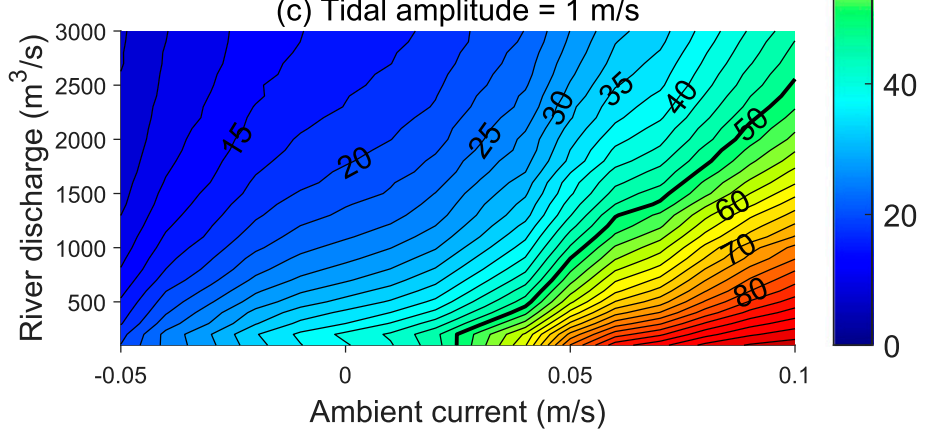

(\%)

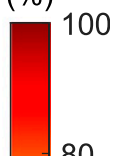

80

60

0

20

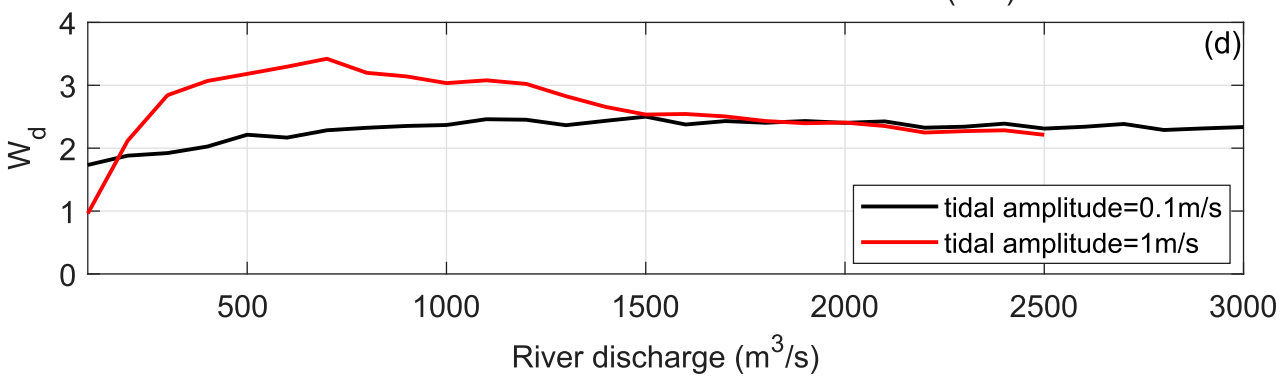

FIG. 14. (a) Model domain and bathymetry of the idealized numerical model. The percent of low-salinity water in the upstream direction [denoted by the dashed line in (a)] under the condition of ambient current ranging from -0.05 to $0.1 \mathrm{~m} \mathrm{~s}^{-1}$ and river discharge varying from 100 to $3000 \mathrm{~m}^{3} \mathrm{~s}^{-1}$ with the tidal amplitude of (b) 0.1 and (c) $1 \mathrm{~m} \mathrm{~s}^{-1}$ around the river mouth. (d) The $W_{d}$ variation with river discharge under different tidal current amplitudes.

define $V_{\mathrm{amb}}$ as the critical ambient current corresponding to $50 \%$ of freshwater proportion in the upstream area $(50 \%$ line in Figs. 14b,c). For example, $V_{\mathrm{amb}}$ is $0.086 \mathrm{~m} \mathrm{~s}^{-1}$ for the river discharge of $1000 \mathrm{~m}^{3} \mathrm{~s}^{-1}$ in the case when the amplitude of tidal current is $0.1 \mathrm{~m} \mathrm{~s}^{-1}$.

Finally, we obtain the values of $W_{d}$ for the river discharges ranging from 100 to $3000 \mathrm{~m}^{3} \mathrm{~s}^{-1}$ in the cases with two different amplitudes of tidal current (Fig. 14d). When the tidal mixing is weak, i.e., in the case with an amplitude of tidal current as $0.1 \mathrm{~m} \mathrm{~s}^{-1}, W_{d}$ varies around $\sim 2.5$ after river discharge is larger than $500 \mathrm{~m}^{3} \mathrm{~s}^{-1}$ (black line in Fig. 14d). As the tidal mixing becomes stronger in the case with an amplitude of tidal current as $1 \mathrm{~m} \mathrm{~s}^{-1}, W_{d}$ becomes a little larger, but decreases to $\sim 2.5$ after river discharge is larger than $700 \mathrm{~m}^{3} \mathrm{~s}^{-1}$ (red line in Fig. 14d). Therefore, the value of $\sim 2.5$ can be a critical number for the downstream buoyancy driven current to overcome the upstream ambient current and induce the river plume extension from upstream direction to downstream direction under a specific upstream ambient current.
As for the Yellow River, the northward tide-induced residual current acts as the upstream ambient current in the idealized model. The tide-induced residual current north of the river mouth is $\sim 0.03 \mathrm{~m} \mathrm{~s}^{-1}$ in spring tide. From the dimensionless number $W_{d}$ of $\sim 2.5$, we can infer that when the buoyancy driven current is larger than $\sim 0.08 \mathrm{~m} \mathrm{~s}^{-1}$, the plume will turn downstream. We then modeled the Yellow River plume under river discharges ranging from 100 to $1000 \mathrm{~m}^{3} \mathrm{~s}^{-1}$ with an interval of $100 \mathrm{~m}^{3} \mathrm{~s}^{-1}$. As an approximation to the buoyancy driven current, we calculate the differences in residual current between these cases and that in case 2, which are approximately $0.04,0.05,0.06,0.07,0.09,0.10,0.11,0.11,0.12$, and $0.13 \mathrm{~m} \mathrm{~s}^{-1}$ around the river mouth in spring tide. Therefore, according to the critical value of $W_{d}$, the plume will turn to downstream direction when the Yellow River discharge is larger than $500 \mathrm{~m}^{3} \mathrm{~s}^{-1}$ and the buoyancy driven current around the river mouth is larger than $0.08 \mathrm{~m} \mathrm{~s}^{-1}$.

We then calculate the proportion of the freshwater volume in the upstream area (separated by a northward section originated from the river mouth) in spring tide, which are 


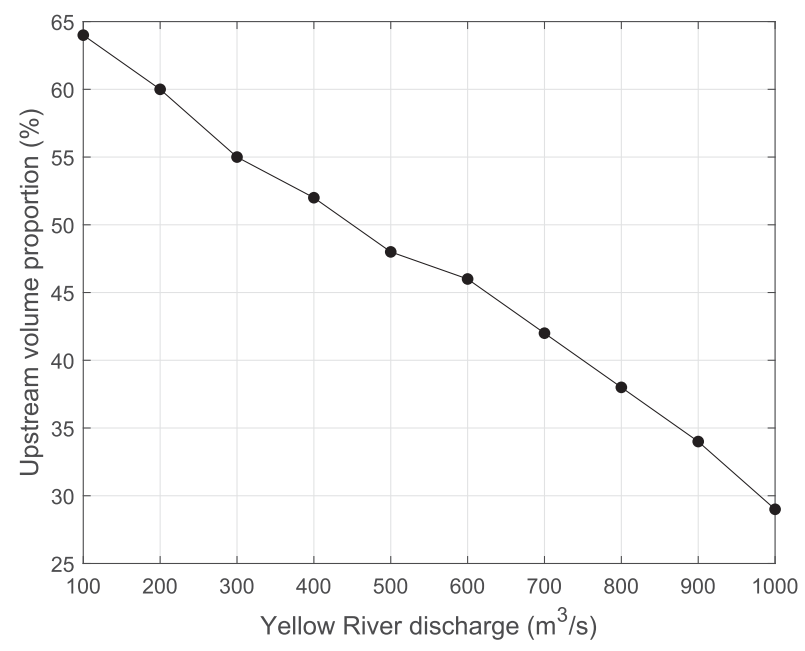

FIG. 15. The variation in the proportion of freshwater volume in the upstream area with the Yellow River discharge ranging from 100 to $1000 \mathrm{~m}^{3} \mathrm{~s}^{-1}$ with an interval of $100 \mathrm{~m}^{3} \mathrm{~s}^{-1}$.

$64 \%, 60 \%, 55 \%, 52 \%, 48 \%, 46 \%, 42 \%, 38 \%, 34 \%$, and $29 \%$ for the cases with river discharge increased from 100 to $1000 \mathrm{~m}^{3} \mathrm{~s}^{-1}$ with an interval of $100 \mathrm{~m}^{3} \mathrm{~s}^{-1}$ (Fig. 15). Apparently, the proportion of freshwater volume in the upstream area decreases with the increasing of river discharge, which is consistent with the results of the idealized model. Because of the temporal variations in ambient current (tide-induced residual current around the Yellow River mouth), we cannot obtain the exact values for the proportion of the freshwater volume in the upstream area as those in the idealized model. However, the proportion becomes smaller than $50 \%$ after the Yellow River discharge is larger than $500 \mathrm{~m}^{3} \mathrm{~s}^{-1}$, which is consistent with the river discharge inferred from the $W_{d}$ and suggest the application of $W_{d}$ in the Yellow River.

From above analysis, we also note that the effect of tide on the river plume has two aspects. As mentioned in the introduction and indicated from the idealized model result, tidal mixing plays an important role in prohibiting the upstream extension of river plume. However, the tide-induced residual current in the Yellow River, which plays a similar role as an upstream ambient current in the idealized model, can promote the upstream extension of the river plume. In the condition of low Yellow River discharge, the role of tide-induced residual current is more important than that of tidal mixing in spring tide, which induces the upstream extension of the plume. Moreover, under such specified tide-induced residual current, there exists a critical Yellow River discharge that determines the extension direction of the plume. As the Yellow River
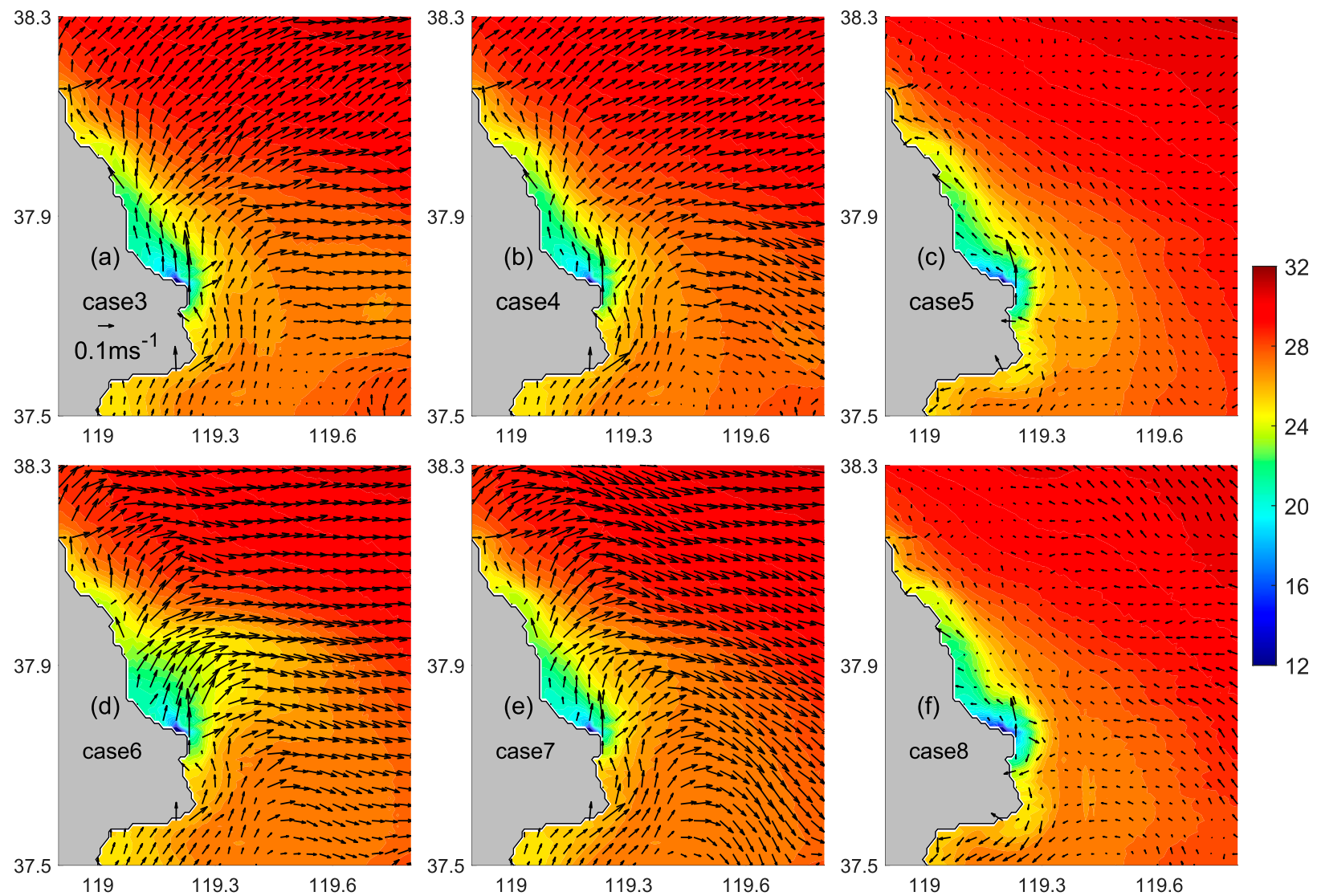

FIG. 16. Horizontal distribution of sea surface salinity (color) and residual current (arrow) in (a) case 3, (b) case 4, and (c) case 5 on 11 Jun and (d) case 6 , (e) case 7 , and (f) case 8 on 19 Jun. 
discharge is larger than the critical value, the plume turns downstream.

\section{c. Influence of summer wind on the upstream extension of the plume}

The influences of tide and river discharge on the upstream extension of the Yellow River plume have been presented in sections $4 \mathrm{a}$ and $4 \mathrm{~b}$. Here, we examine the influence of winds on the upstream extension of the Yellow River plume using cases 3-8 (Table 2).

Generally, the pattern of upstream extension of the Yellow River plume in spring tide does not change under the influence of southerly wind (Fig. 16a), southwesterly wind (Fig. 16b), and northeasterly wind (Fig. 16c). In all three cases, the Yellow River plume still moves in upstream direction. Furthermore, the wind-induced residual current appears mainly outside the plume, which flows northeastward in cases 3 and 4, and southwestward in case 5. Consequently, summer wind has little influence on the upstream extension of the Yellow River plume under the low river discharge condition in spring tide.

We also check the influence of the same three wind conditions on the river plume in neap tide (Figs. 16d-f). Results show that the influence of wind on the plume is larger than that in spring tide. The low-salinity water is moved eastward by the southerly and southwesterly wind (Figs. 16d,e), and distributes closely to the coast by the northeasterly wind (Fig. 16f). Furthermore, the wind-driven currents inside the plume are also stronger in neap tide than in spring tide due to the smaller vertical eddy coefficient in neap tide and therefore reduction of Ekman layer thickness.

\section{d. General discussion on the upstream extension of river plumes}

As mentioned in the introduction, upstream extension of the river plume has been frequently found in numerical simulations (Chao and Boicourt 1986; Chapman and Lenz 1994; Kourafalou et al. 1996; Yankovsky and Chapman 1997; Yankovsky 2000; Garvine 2001; Guo and Valle-Levison 2007; Matano and Palma 2010; Wu et al. 2011). Different mechanisms have been proposed, including model configuration (Yankovsky 2000; Garvine 2001), geostrophic adjustment (Chapman and Lenz 1994; Matano and Palma 2010), and nongeostrophic acceleration (Kourafalou et al. 1996). Tide has been considered as an important effect to restrict the upstream extension of the river plumes (Isobe 2005; Guo and Valle-Levison 2007; Wu et al. 2011). In both the Chesapeake Bay (Guo and Valle-Levison 2007) and Changjiang River (Wu et al. 2011), the plumes extend upstream in the numerical experiment without tide, but turn downstream when the tide is considered.

However, in our study, the strong tidal current has the effect to promote the upstream extension of the Yellow River plume under low river discharge condition. The strong tidal current in spring tide intensifies the upstream tide-induced residual current, and the strong tidal mixing weakens the downstream density-driven current. The combination of weakened downstream density-driven current and intensified upstream tide-induced residual current promotes the upstream extension of the plume in spring tide under low river discharge condition. The opposite situation occurs in neap tide when the plume moves in the downstream direction. It must be noted that such transition from spring tide to neap tide cannot be maintained under high river discharge condition when the tidal mixing and tide-induced residual current cannot compete with the buoyancy effect given by the river discharge.

Although these points are specific to our study area, they are different from the previous understanding on the effects of tide on river plume (Isobe 2005; Guo and Valle-Levison 2007; Wu et al. 2011). Furthermore, tide-induced residual current has been reported in many coastal regions, such as the East China Sea (Tang 1988), the North Sea (Lwiza et al. 1991), and the Seto Inland Sea (Chang et al. 2009). In the regions of river water influence, coastline and bathymetry usually change largely, which is favorable to the generation of tide-induced residual current, which, as shown in this study, probably influences the river plume as an ambient current. Therefore, it is necessary to put this mechanism in mind when examining the behavior of river plume in a tide-dominated area with a largely changed coastline or bathymetry.

\section{Conclusions}

Both the hydrographic data and modeling results show that the Yellow River plume propagates upstream under the low river discharge condition in summer, but turns downstream under the high river discharge condition. The numerical experiments demonstrate that the upstream extension under the low river discharge condition has significant spring and neap tidal variations. In spring tide, the Yellow River plume extends in the upstream direction, whereas in neap tide, the plume propagates in the downstream direction. Freshwater volume transport analysis shows that the different transport of freshwater in spring tide and neap tide are mainly contributed by the subtidal process. The strong (weak) northward tide-induced residual current and the weak (strong) southward densitydriven current cause the upstream (downstream) extension of the plume in spring (neap) tide. Momentum analysis confirms the important roles of advection term and viscosity term in the condition of low river discharge. Therefore, both the tideinduced residual current and tidal mixing are important for the upstream extension of the Yellow River plume under low river discharge condition. Summer wind has little influence on the upstream extension of the Yellow River plume in spring tide, whereas its influence on the plume in neap tide is a little stronger.

River discharge can change the upstream extension of the Yellow River plume, which turns downstream when the river discharge increases. The upstream tide-induced residual current cannot compete with the downstream density-driven current and the plume consequently turns downstream. Momentum balance demonstrates that the Yellow River plume in the high river discharge condition is controlled mainly by a geostrophic balance. An idealized model study suggests that a dimensionless number of $\sim 2.5$, the ratio of buoyancy driven current to upstream ambient current, can be used to 
know the river discharge that changes the plume extension from upstream to downstream under a specific upstream ambient current.

This study emphasizes the importance of tide and river discharge on the river plume. Differing from previous studies, which suggested that tide can prohibit the upstream extension of river plume, our study find that tide can promote the upstream extension of the plume. Therefore, the effect and mechanism of tide on the river plume should be examined case by case. On the other hand, the river discharge can also influence the extension of the river plume. As the river discharge is large enough, it can overcome the effect of an upstream ambient current and turn the plume downstream.

Acknowledgments. The authors thank the two anonymous reviewers for their helpful suggestions on original manuscript. This study was supported by the National Natural Science Foundation of China (41906010), the National Natural Science Foundation of China-Shandong Joint Fund (U1906215, U1806211), the Postdoctoral Research Foundation of China (2018M642701). X. Guo thanks support from the Fundamental Research Funds for Central Universities of the Ministry of Education of China (201512004). T. Zou thanks support from the National Natural Science Foundation of China (41406029). We also thank support from the Youth Foundation of the Shandong Academy of Sciences (2019QN0026).

\section{REFERENCES}

Beardsley, R. C., R. Limeburner, D. Hu, K. Le, and G. A. Cannon, 1985: Discharge of the Changjiang (Yangtze River) into the East China Sea. Cont. Shelf Res., 4, 57-76, https://doi.org/ 10.1016/0278-4343(85)90022-6.

Blumberg, A. F., and G. L. Mellor, 1987: A description of a threedimensional coastal ocean circulation model. Three-Dimensional Coastal Ocean Models, Coastal Estuarine Sciences Series, Vol. 4, Amer. Geophys. Union, 1-16, https://doi.org/10.1029/ CO004p0001.

Chang, P.-H., X. Guo, and H. Takeoka, 2009: A numerical study of the seasonal circulation in the Seto Inland Sea, Japan. J. Oceanogr., 65, 721-736, https://doi.org/10.1007/s10872-0090062-4.

Chao, S.-Y., and W. C. Boicourt, 1986: Onset of estuarine plumes. J. Phys. Oceanogr., 16, 2137-2149, https://doi.org/10.1175/ 1520-0485(1986)016<2137:OOEP > 2.0.CO;2.

Chapman, D. C., and S. J. Lenz, 1994: Trapping of a coastal density front by the bottom boundary layer. J. Phys. Oceanogr., 24, 1464-1479, https://doi.org/10.1175/1520-0485(1994)024<1464: TOACDF $>2.0 . C O ; 2$.

Dou, Z., Y. Luo, K. Huang, C. Zhang, L. Li, G. Cai, and H. Ning, 1981: Numerical computation of tidal current and tideinduced residual circulation of the Bohai Sea. Acta Oceanol. Sin., 3, 355-369.

Fang, G., 1986: Tide and tidal current charts for the marginal seas adjacent to China. Chin. J. Oceanol. Limnol., 4, 1-16, https:// doi.org/10.1007/BF02850393.

_- and J. Yang, 1985: A two-dimensional numerical model of the tidal motions in the Bohai Sea. Chin. J. Oceanol. Limnol., 3, 135-152, https://doi.org/10.1007/BF02906791.

Garvine, R. W., 1995: A dynamical system for classifying buoyant coastal discharge. Cont. Shelf Res., 15, 1585-1596, https:// doi.org/10.1016/0278-4343(94)00065-U.
- 2001: The impact of model configuration in studies of buoyant coastal discharge. J. Mar. Res., 59, 193-225, https://doi.org/ 10.1357/002224001762882637.

Guan, B., and S. Chen, 1964: The current systems in the nearsea area of the China Seas. Report of Comprehensive Oceanographic Survey in Chinese Oceans in 1958 (in Chinese), Vol. 5, Ocean Comprehensive Survey Office, Ocean Division, State Science and Technology Committee, 1-85.

Guo, X., and A. Valle-Levison, 2007: Tidal effects on estuarine circulation and outflow plume in the Chesapeake Bay. Cont. Shelf Res., 27, 20-42, https://doi.org/10.1016/j.csr.2006.08.009.

Hanawa, K., and H. Mitsudera, 1985: On daily average of oceanographic data (in Japanese). Coastal Oceanogr. Bull., 23, 79-87.

Huang, D., J. Su, and J. O. Backhaus, 1999: Modelling the seasonal thermal stratification and baroclinic circulation in the Bohai Sea. Cont. Shelf Res., 19, 1485-1505, https://doi.org/10.1016/ S0278-4343(99)00026-6.

Isobe, A., 2005: Ballooning of river-plume bulge and its stabilization by tidal currents. J. Phys. Oceanogr., 35, 2337-2351, https://doi.org/10.1175/JPO2837.1.

Jurisa, J. T., and R. Chant, 2012: The coupled Hudson River estuarine-plume response to variable wind and river forcings. Ocean Dyn., 62, 771-784, https://doi.org/10.1007/s10236-0120527-7.

Kasai, A., A. E. Hill, T. Fujiwara, and J. H. Simpson, 2000: Effect of the Earth's rotation on the circulation in regions of freshwater influence. J. Geophys. Res., 105, 16 961-16 969, https://doi.org/ 10.1029/2000JC900058.

Kourafalou, V. H., L. Y. Oey, J. D. Wang, and T. N. Lee, 1996: The fate of river discharge on the continental shelf. 1. Modeling the river plume and inner shelf coastal current. J. Geophys. Res., 101, 3415-3434, https://doi.org/10.1029/95JC03024.

Li, M., and Z. Rong, 2012: Effect of tides on freshwater and volume transports in the Changjiang River plume. J. Geophys. Res., 117, C06027, https://doi.org/10.1029/2011JC007716.

Lin, C., J. Su, B. Xu, and Q. Tang, 2001: Long-term variations of temperature and salinity of the Bohai Sea and their influence on its ecosystem. Prog. Oceanogr., 49, 7-19, https://doi.org/ 10.1016/S0079-6611(01)00013-1.

Lwiza, K. M. M., D. G. Bowers, and J. H. Simpson, 1991: Residual and tidal flow at a tidal mixing front in the North Sea. Cont. Shelf Res., 11, 1379-1395, https://doi.org/10.1016/0278-4343(91)90041-4.

Magome, S., and A. Isobe, 2003: Current structure and behaviour of the river plume in Suo-Nada. J. Oceanogr., 59, 833-843, https://doi.org/10.1023/B:JOCE.0000009574.12925.16.

Matano, R. P., and E. D. Palma, 2010: The upstream spreading of bottom-trapped plumes. J. Phys. Oceanogr., 40, 1631-1650, https://doi.org/10.1175/2010JPO4351.1.

Mellor, G. L., 2003: User guide for a three-dimensional, primitive equation, numerical ocean model (2009 version). Atmospheric and Oceanic Sciences Program, Princeton University Rep., $53 \mathrm{pp}$.

— model for geophysical fluid problems. Rev. Geophys., 20, 851875, https://doi.org/10.1029/RG020i004p00851.

Smagorinsky, J. S., 1963: General circulation experiments with the primitive equations. I. The basic experiment. Mon. Wea. Rev., 91, 99-164, https://doi.org/10.1175/1520-0493(1963)091<0099: GCEWTP $>2.3$.CO;2.

Tang, Y., 1988: Numerical modelling of the tide-induced residual current in the East China Sea. Prog. Oceanogr., 21, 417-429, https://doi.org/10.1016/0079-6611(88)90018-3. 
Wang, H., Z. Yang, Y. Saito, J. Liu, and X. Sun, 2006: Interannual and seasonal variation of the Huanghe (Yellow River) water discharge over the past 50 years: Connections to impacts from ENSO events and dams. Global Planet. Change, 50, 212-225, https://doi.org/10.1016/j.gloplacha.2006.01.005.

Wang, Q., X. Guo, and H. Takeoka, 2008: Seasonal variations of the Yellow River plume in the Bohai Sea: A model study. J. Geophys. Res., 113, C08046, https://doi.org/10.1029/ 2007JC004555.

Wang, Y., Z. Liu, H. Gao, L. Ju, and X. Guo, 2011: Response of salinity distribution around the Yellow River mouth to abrupt changes in river discharge. Cont. Shelf Res., 31, 685-694, https://doi.org/10.1016/j.csr.2011.01.005.

Wei, H., D. Hainbucher, T. Pohlmann, S. Feng, and J. Suendermann, 2004: Tidal-induced Lagrangian and Eulerian mean circulation in the Bohai Sea. J. Mar. Sysm., 44, 141-151, https:// doi.org/10.1016/j.jmarsys.2003.09.007.

Whitney, M. M., and R. W. Garvine, 2005: Wind influence on a coastal buoyant outflow. J. Geophys. Res., 110, C03014, https:// doi.org/10.1029/2003JC002261.

Wong, K. C., 1994: On the nature of transverse variability in a coastal plain estuary. J. Geophys. Res., 99, 14209-14222, https://doi.org/10.1029/94JC00861.

Wu, D., L. Mu, Q. Li, X. Bao, and X. Wan, 2004: Long-term variation characteristics of the salinity of the Bohai Sea and the probable leading factors (in Chinese). Prog. Nat. Sci., 14, 191-195.
Wu, H., J. Zhu, J. Shen, and H. Wang, 2011: Tidal modulation on the Changjiang River plume in summer. J. Geophys. Res., 116, C08017, https://doi.org/10.1029/2011JC007209.

_ J. Shen, J. Zhu, J. Zhang, and L. Li, 2014: Characteristics of the Changjiang plume and its extension along the Jiangsu Coast. Cont. Shelf Res., 76, 108-123, https://doi.org/10.1016/ j.csr.2014.01.007.

Yankovsky, A. E., 2000: The cyclonic turning and propagation of buoyant coastal discharge along the shelf. J. Mar. Res., 58, 585-607, https://doi.org/10.1357/002224000321511034.

— - and D. C. Chapman, 1997: A simple theory for the fate of buoyant coastal discharges. J. Phys. Oceanogr., 27, 1386-1401, https://doi.org/10.1175/1520-0485(1997)027<1386: ASTFTF $>2.0 . \mathrm{CO} ; 2$.

— B. M. Hickey, and A. K. Munchow, 2001: Impact of variable in flow on the dynamics of a coastal buoyant plume. J. Geophys. Res., 106, 19809-19824, https://doi.org/10.1029/ 2001JC000792.

Zhao, B., G. Zhuang, D. Cao, and F. Lei, 1995: Circulation, tidal residual currents and their effects on the sedimentations in the Bohai Sea. Oceanol. Limnol. Sin., 26, 466-473.

Zhou, S., S. Ma, C. Li, and D. Qiu, 1991: Hydrographic chart for reproduction environment in the Bohai Sea (in Chinese). Mar. Fish. Res., 12, 93-122.

— J. Chen, S. Ma, and J. Zhao, 1997: The hydrological environment and variation features of enhancement in Bohai Sea (in Chinese). Mar. Fish. Res., 18, 86-100. 